\title{
Quantification of ice production in Laptev Sea polynyas and its sensitivity to thin-ice parameterizations in a regional climate model
}

\author{
Oliver Gutjahr, Günther Heinemann, Andreas Preußer, Sascha Willmes, and Clemens Drüe \\ Department of Environmental Meteorology, University of Trier, Behringstraße 21, 54296 Trier, Germany
}

Correspondence to: Oliver Gutjahr (gutjahr@uni-trier.de)

Received: 6 April 2016 - Published in The Cryosphere Discuss.: 25 May 2016

Revised: 19 October 2016 - Accepted: 9 November 2016 - Published: 9 December 2016

\begin{abstract}
The quantification of sea-ice production in the Laptev Sea polynyas is important for the Arctic sea-ice budget and the heat loss to the atmosphere. We estimated the ice production for the winter season 2007/2008 (NovemberApril) based on simulations with the regional climate model COSMO-CLM at a horizontal resolution of $5 \mathrm{~km}$ and compared it to remote sensing estimates. A reference and five sensitivity simulations were performed with different assumptions on grid-scale and subgrid-scale ice thickness considered within polynyas, using a tile approach for fractional sea ice. In addition, the impact of heat loss on the atmospheric boundary layer was investigated.

About $29.1 \mathrm{~km}^{3}$ of total winter ice production was estimated for the reference simulation, which varies by up to $+124 \%$ depending on the thin-ice assumptions. For the most realistic assumptions based on remote sensing of ice thickness the ice production increases by $+39 \%$. The use of the tile approach enlarges the area and enhances the magnitude of the heat loss from polynyas up to $+110 \%$ if subgrid-scale open water is assumed and by $+20 \%$ for realistic assumptions. This enhanced heat loss causes in turn higher ice production rates and stronger impact on the atmospheric boundary layer structure over the polynyas. The study shows that ice production is highly sensitive to the thin-ice parameterizations for fractional sea-ice cover. In summary, realistic ice production estimates could be retrieved from our simulations. Neglecting subgrid-scale energy fluxes might considerably underestimate the ice production in coastal polynyas, such as in the Laptev Sea, with possible consequences on the Arctic sea-ice budget.
\end{abstract}

\section{Introduction}

The rate of sea-ice growth strongly depends on the energy fluxes at the ice or ocean surface. If the total atmospheric heat flux is negative, the ocean loses heat either directly to the atmosphere or via conduction through an existing sea-ice cover. In the former case frazil ice forms, which aggregates subsequently to a new thin-ice layer under calm conditions. In the latter case basal freezing occurs to balance this heat loss. Most of the heat loss from the ocean occurs over open water or thin-ice areas, such as leads and polynyas, within an otherwise compact sea-ice cover (Smith et al., 1990; Morales Maqueda et al., 2004). Although the fraction of such areas in polar oceans is relatively small during winter, they are of major importance for the heat budget of the atmospheric boundary layer (ABL) (Heinemann and Rose, 1990; Haid et al., 2015) and the ocean circulation, such as the Arctic circumpolar boundary current (e.g. Aksenov et al., 2011; Rudels et al., 1999).

The Laptev Sea (Siberia) is a very shallow shelf sea with water depths between 15 and $200 \mathrm{~m}$ and comprises an area of about $500 \times 10^{3} \mathrm{~km}^{2}$ (Timokhov, 1994; Krumpen et al., 2013). It is one of the most significant regions where a considerable amount of the total Arctic sea ice is produced (Aagard et al., 1981; Dmitrenko et al., 2009; Dethleff et al., 1998; Willmes et al., 2011a; Tamura and Ohshima, 2011; Iwamoto et al., 2014). The newly formed sea ice is subsequently transported by the Transpolar Drift Stream and accounts for about $20 \%$ of the total ice export through Fram Strait (Rigor and Colony, 1997). The Laptev Sea thus plays a key role for future Arctic sea-ice development (Krumpen et al., 2013). 
Quasi-stationary latent-heat or flaw polynyas reoccur frequently along the Siberian coast and along the fast-ice edge (Dmitrenko et al., 2001; Krumpen et al., 2011; Bareiss and Görgen, 2005) due to offshore wind stress (Smith et al., 1990; Dmitrenko et al., 2001; Morales Maqueda et al., 2004; Krumpen et al., 2011; Willmes et al., 2011a; Dmitrenko et al., 2012). These polynyas are narrow, long bands of open water and/or thin ice, which separate landfast ice from seaward drifting ice on the Siberian continental shelves during winter (Dethleff et al., 1998), predominantly from October until June (Bareiss and Görgen, 2005). In general, the ice cover in the Laptev Sea can be divided into three regimes: fast ice, pack ice, and flaw polynyas in between (Eicken et al., 2005).

Particularly in winter, sea water at the freezing point is directly exposed to a cold atmosphere, resulting in intense ice formation (Dethleff et al., 1998). Due to this strong surface heat loss within coastal polynyas frazil ice forms, which is subsequently transported toward the downwind edge of the polynyas (Smith et al., 1990; Morales Maqueda et al., 2004; Krumpen et al., 2011; Willmes et al., 2010). This process creates a spatial gradient of thin-ice thickness (TIT) increasing from open-water conditions at the windward polynya edge to thicker ice at the downwind side. Here, at the polynya edge, the advected frazil ice accumulates to a thin layer (Martin and Kauffmann, 1981; Krumpen et al., 2011), which thickens and consolidates before it drifts further offshore. During the ice formation, salt is excluded from the ice matrix and is drained as brine from the sea ice (Krumpen et al., 2011). This salt input induces haline convection and erodes the density stratification of the underlying water column (Ivanov and Golovin, 2007; Bauch et al., 2009) and, if penetrative, dense bottom water forms (Backhaus et al., 1997; Bauch et al., 1995). The long-term mean probability for convective mixing down to the seafloor is only about $20 \%$ in the western and about $70 \%$ in the eastern Laptev Sea (Dmitrenko et al., 2005; Krumpen et al., 2011), which is owed to the general preservation of the stratification throughout the winter caused by freshwater input from the Lena River during summer (Bauch et al., 2009; Dmitrenko et al., 2005). The cold, dense bottom water contributes to the Arctic halocline (Bauch et al., 2009) and thermohaline structure in the Eurasian Basin (Johnson and Polyakov, 2001).

The horizontal resolution of regional climate models is generally too coarse to represent leads and small polynyas explicitly. Therefore, they have to be treated as inhomogeneities of momentum and energy fluxes on a subgrid scale. Heinemann and Kerschgens (2005) investigated three approaches to account for such subgrid-scale inhomogeneities within a model grid box: the (i) aggregation, (ii) mosaic, and (iii) tile approach (TA). In the aggregation approach the parameters for the fluxes (such as roughness length or albedo) are weight-averaged over different surface types within a grid box and then the fluxes are calculated from these grid-scale means. In contrast, in the mosaic approach the fluxes are explicitly calculated on a sub-scale grid and averaged after- wards. In the standard version (v5.0_clm1) of the regional climate model COnsortium for Small-scale MOdel - Climate Limited area Mode (COSMO-CLM or CCLM; Rockel et al., 2008), which is the climate version of the numerical weather prediction model COSMO of the German Meteorological Service (Steppeler et al., 2003), a model grid box is assumed to be either completely covered with sea ice or completely ice free. However, if neglecting subgrid-scale energy fluxes or heat loss from open-water or thin-ice areas, the energy transfer is underestimated and subsequently also the sea-ice production (IP). This underestimation affects the sea-ice budget and associated processes connected to the ocean, such as salt release and deep water formation (Martin and Cavalieri, 1989; Bauch et al., 1995; Ivanov and Golovin, 2007). Although the ocean processes are not represented in CCLM, the quantification of IP can be seen as a proxy for dense water formation.

In other regional climate models, such as the Polar Weather Research and Forecasting (Polar-WRF) model, fractional sea ice is already a default option with the assumption of subgrid-scale open water and with fixed sea-ice concentrations (SIC) and ocean temperatures during a $48 \mathrm{~h}$ simulation (Bromwich et al., 2009). However, assumptions have to be made for the subgrid-scale thin-ice thickness, since particularly in winter leads and polynyas are rarely ice free (Willmes et al., 2010, 2011a; Adams et al., 2013).

In the following we quantify the sea-ice production in the Laptev Sea polynyas (Siberia) and investigate its sensitivity on the assumptions of thin-ice thickness associated with the tile approach. The sea-ice module of Schröder et al. (2011) was already successfully applied in the Laptev Sea by Ebner et al. (2011), who could show that polynyas significantly affect the ABL. More recently, Bauer et al. (2013) calculated sea-ice production rates for this region based on COSMO simulations with an assumed thin-ice thickness of $10 \mathrm{~cm}$ (B10) or open water (B00) within polynyas. Their model results showed that the presence of grid-scale thin ice affects the IP considerably.

The implementation of a TA for subgrid-scale energy fluxes constitutes, from a physical point of view, an improvement to the representation of polynyas in regional climate models. However, it is unclear how sensitive the energy fluxes, the resulting IP, and the ABL are to the choice of gridscale and subgrid-scale ice thickness. By varying the thinice thickness in a sensitivity experiment, we aim to quantify these uncertainties. As a benchmark for our study we use the IP estimations of Willmes et al. (2011a, b). We further comprise model results of Bauer et al. (2013) and derived IP from Moderate Resolution Imaging Spectroradiometer (MODIS) data.

This paper is structured as follows: in Sect. 2, a short overview of the model configuration and the study region is given; in Sect. 3 the basics of the sea-ice module are described (see details in Appendices A and B). The model is validated with in situ data in Sect. 4 and the effects on the 


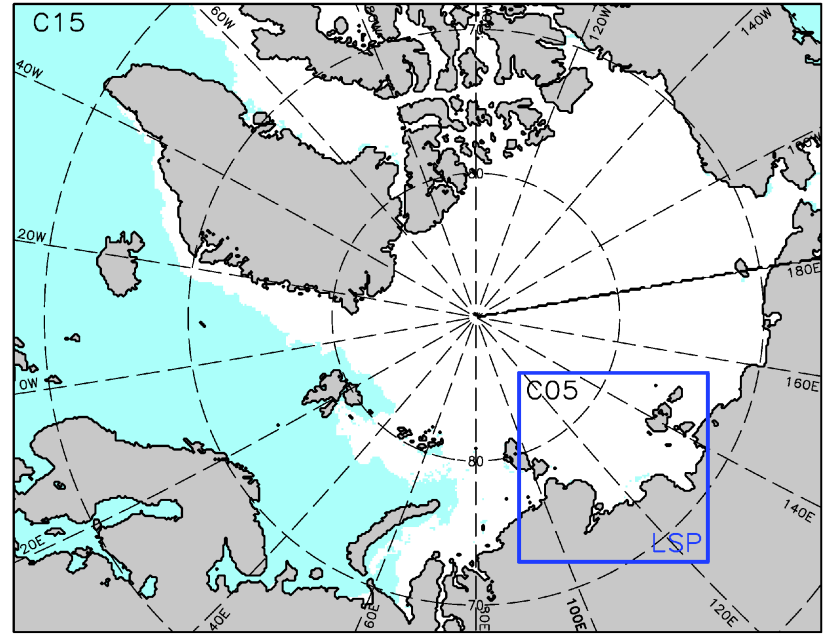

Figure 1. Model domains of COSMO-CLM at a horizontal resolution of $15 \mathrm{~km}$ (C15, whole Arctic). The study domain of the Laptev Sea polynyas (LSP) with a resolution of $5 \mathrm{~km}$ (C05, blue box) is shown in detail in Fig. 2. The sea-ice extent (white shaded) is from 4 January 2008.

atmospheric boundary layer and on ice production rates are presented in Sects. 5 and 6 and discussed with respect to remote sensing estimates in Sect. 7. Finally, we conclude in Sect. 8 .

\section{CCLM configuration and model domains}

The domain of CCLM (Fig. 1) covers the whole Arctic at a horizontal resolution of $15 \mathrm{~km}$ (C15). CCLM was run on $450 \times 350$ grid boxes and with 42 vertical layers, of which 16 are below $2 \mathrm{~km}$ height. Nested within, we performed simulations for the Laptev Sea (Fig. 2 and Table 1) at $5 \mathrm{~km}$ resolution (C05) with $260 \times 260$ grid boxes and 60 vertical levels, of which 24 levels are below $2 \mathrm{~km}$ height. We subdivided this domain into four polynya regions, which have been already used in previous studies, e.g. by Willmes et al. (2011a): the north-eastern Taimyr polynya (NET), the Taimyr polynya (T), the Anabar-Lena polynya (AL), and the western New Siberian polynya (WNS). The total area of the masks is $26.19 \times 10^{4} \mathrm{~km}^{2}$.

The $\mathrm{C} 15$ model is forced by ERA-Interim data (Dee et al., 2011) with updates to the lateral boundaries every $6 \mathrm{~h}$. The C05 models are then forced by the output of $\mathrm{C} 15$ with an update frequency of $1 \mathrm{~h}$. The models were run in a forecasting procedure for the winter period November 2007 to April 2008 (182 days in total). They were restarted every simulation day at 18:00 UTC and simulated the following $30 \mathrm{~h}$. Thereby the initial sea-ice conditions (see Sect. 3.2) were prescribed to the sea-ice concentration and thickness of the following day. The first $6 \mathrm{~h}$ were cut off as spin-up. The

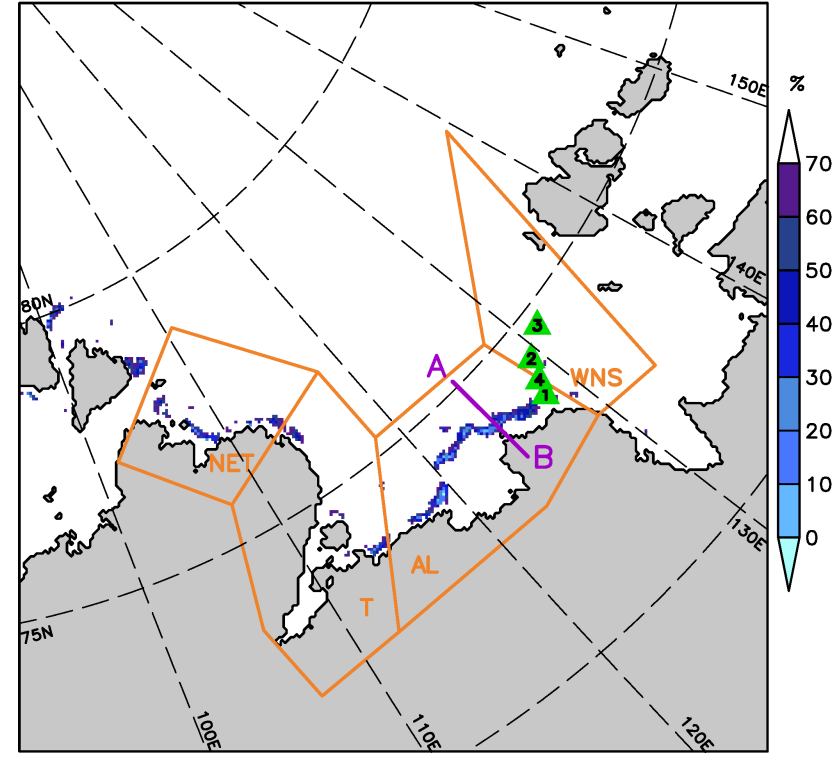

Figure 2. Model domain at $5 \mathrm{~km}$ resolution (C05) over the Laptev Sea (approximately $1500 \mathrm{~km} \times 1500 \mathrm{~km}$ ) with the sea-ice concentration from AMSR-E showing open polynyas $(\leq 70 \%)$ on 4 January 2008 . Four polynya regions are superimposed as orange polygons: north-eastern Taimyr polynya (NET), the Taimyr polynya (T), the Anabar-Lena polynya (AL), and the western New Siberian polynya (WNS). A $\rightarrow$ B denotes the $214 \mathrm{~km}$ long cross section (magenta) used in Sect. 5. The locations of the four AWS stations are marked with green triangles.

simulation output (00:00-23:00 UTC) was stored at a temporal resolution of $1 \mathrm{~h}$.

Surface fluxes were calculated by a bulk transfer scheme with a stability dependence (Louis, 1979) (see Appendix B3). The vertical diffusion was parameterized by a level- 2.5 closure scheme (Mellor and Yamada, 1974) based on a prognostic equation for turbulent kinetic energy (TKE). Radiation processes were calculated hourly using the Ritter and Geleyn (1992) scheme extended for ice clouds. We applied a RungeKutta scheme of third order (Wicker and Skamarock, 2002). Additionally, a fast-wave solver for sound and gravity waves was used (Baldauf, 2013). All simulations were run without spectral nudging.

To improve the simulation of heat loss over fractional sea ice in CCLM, we modified the standard version with regard to the following points: (i) we implemented the thermodynamic two-layer sea-ice module of Schröder et al. (2011), (ii) we used daily sea-ice thickness (SIT) fields from the PanArctic Ice-Ocean Modeling and Assimilation System (PIOMAS) data set (Zhang and Rothrock, 2003) as initial data, (iii) we implemented a new albedo scheme for sea ice based on Køltzow (2007), and (iv) we implemented a tile approach for the energy balance over fractional sea ice. The TA is a simplification of the mosaic approach, considering only the percentage of different surface types but not their exact 
Table 1. Overview of the performed simulations with COSMO-CLM for the winter period 2007/2008. The grid-scale thin-ice thickness (TIT) within polynyas (ice concentration: $0<\mathrm{SIC} \leq 70 \%$ ) is shown in centimetres and the assumed subgrid-scale TIT is shown in parentheses. The latter is only required if the tile approach (TA) is used.

\begin{tabular}{lrlrll}
\hline Model run & $\Delta x$ & Region & TIT $[\mathrm{cm}]$ & TA & Information \\
\hline C15 & $15 \mathrm{~km}$ & Arctic & $10(-)$ & no & forced by ERA-Interim \\
C05-ref & $5 \mathrm{~km}$ & Laptev Sea & $10(-)$ & no & reference run \\
C05-10/0 & $5 \mathrm{~km}$ & Laptev Sea & $10(0)$ & yes & subgrid-scale open water \\
C05-10/1 & $5 \mathrm{~km}$ & Laptev Sea & $10(1)$ & yes & \\
C05-10/10 & $5 \mathrm{~km}$ & Laptev Sea & $10(10)$ & yes & \\
C05-50/5 & $5 \mathrm{~km}$ & Laptev Sea & $50(5)$ & yes & \\
C05-50/1 & $5 \mathrm{~km}$ & Laptev Sea & $50(1)$ & yes & realistic assumptions \\
\hline
\end{tabular}

location. According to Heinemann and Kerschgens (2005) the TA provides similarly good results as the mosaic approach, but with distinctly less computation time. Thus, we decided to implement this variant. First steps in the direction of a tile approach in CCLM were made by Van Pham et al. (2014). However, their adjustments were limited to area-weighted albedo values and to surface roughness values within a grid box that is covered with fractional sea ice. Although points (ii)-(iii) represent new modifications to CCLM as well, we accept them as the default option for our simulations.

The C15 simulation was performed without a TA in order to introduce effects from the TA only through the $5 \mathrm{~km}$ simulations. In case of $\mathrm{C} 05$, we performed a reference simulation in the Laptev Sea area without a TA (C05-ref) and five sensitivity simulations with the TA. The configuration of the reference simulation is similar (as far as possible) to the configuration of the previous studies of Bauer et al. (2013), where no TA was available. However, they used an older model version, which causes differences. C05-ref is thus comparable to the simulations of Bauer et al. (2013) and further the reference without TA for our sensitivity simulations.

While the sea-ice thickness outside the polynyas was specified as explained in Sect. 3.2, the ice thickness within the polynya areas has to be prescribed. For C15 and C05-ref the ice thickness in polynyas areas is generally $10 \mathrm{~cm}$, but we assume $1 \mathrm{~cm}$ thin ice at polynya grid boxes in C05-ref, where the sea-ice concentration is $0 \%$. Such areas particularly produce new ice and consist of a mixture of open water, grease and frazil ice, and thin solid ice. However, in winter openwater areas occur mostly at the windward side of polynyas, which is only a small fraction of the entire polynya area.

For three of the five sensitivity simulations we assumed also a grid-scale ice thickness of $10 \mathrm{~cm}$ for polynyas and assumed either subgrid-scale open water (C05-10/0) or a subgrid-scale TIT of $1 \mathrm{~cm}(\mathrm{C} 05-10 / 1)$ and $10 \mathrm{~cm}(\mathrm{C} 05-$ 10/10). The fourth and fifth sensitivity simulations were configured with a grid-scale ice thickness of $50 \mathrm{~cm}$ and a subgrid-scale TIT of $5 \mathrm{~cm}(\mathrm{C} 05-50 / 5)$ or $1 \mathrm{~cm}(\mathrm{C} 05-50 / 1)$. See Table 1 for an overview of the simulations. The assumption of $10 \mathrm{~cm}$ TIT originates from the fact that the mean

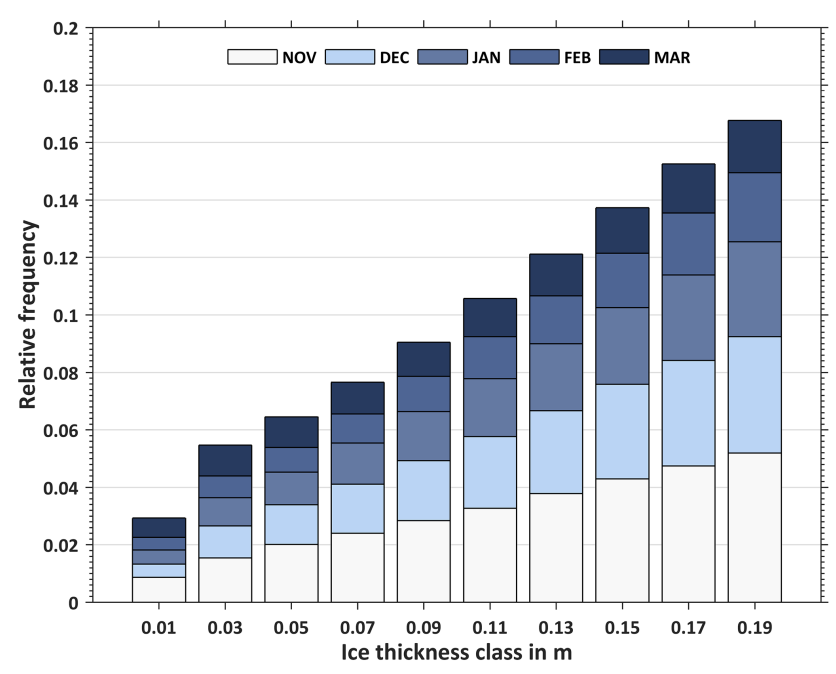

Figure 3. Thin-ice thickness distribution $(\leq 20 \mathrm{~cm})$ in the Laptev Sea derived from MODIS data for the winter periods (NovemberMarch) 2002/2003-2014/2015. The bars indicate the relative distribution of each thickness class from the total number of TIT $\leq 0.2 \mathrm{~m}$ appearances between the winter seasons 2002/2003 and 2014/2015. Contributions of each month with respect to the whole winter season for each thickness class are indicated by the blueish colours (see the legend). The mean thickness ( \pm 1 standard deviation) in this period is $13.5 \pm 0.5 \mathrm{~cm}(8.7 \mathrm{~cm}$ for $\leq 10 \mathrm{~cm})$. In the winter period $2007 / 2008$, the mean is $14.0 \pm 2 \mathrm{~cm}(7.7 \mathrm{~cm}$ for $\leq 10 \mathrm{~cm})$.

TIT below $20 \mathrm{~cm}$, derived from MODIS data, is of the order of $\approx 10 \mathrm{~cm}$. Willmes et al. (2011a) derived a mean thin-ice thickness of $11.6 \mathrm{~cm}$ for November to April (1979-2008), while from the MODIS TIT histogram in Fig. 3 a mean thin-ice thickness of $13.5 \mathrm{~cm}$ for November to March in the period 2002/2003-2014/2015 and of $14 \mathrm{~cm}$ for the winter $2007 / 2008$ results, respectively. In a previous study by Bauer et al. (2013) $10 \mathrm{~cm}$ was thus assumed to be a realistic value for the thin-ice thickness within Laptev Sea polynyas. For better comparisons we assumed $10 \mathrm{~cm}$ as well in our reference simulation (and in two sensitivity runs).

The first three sensitivity simulations investigate the effect of the TA, if even thinner subgrid-scale ice is assumed. The 


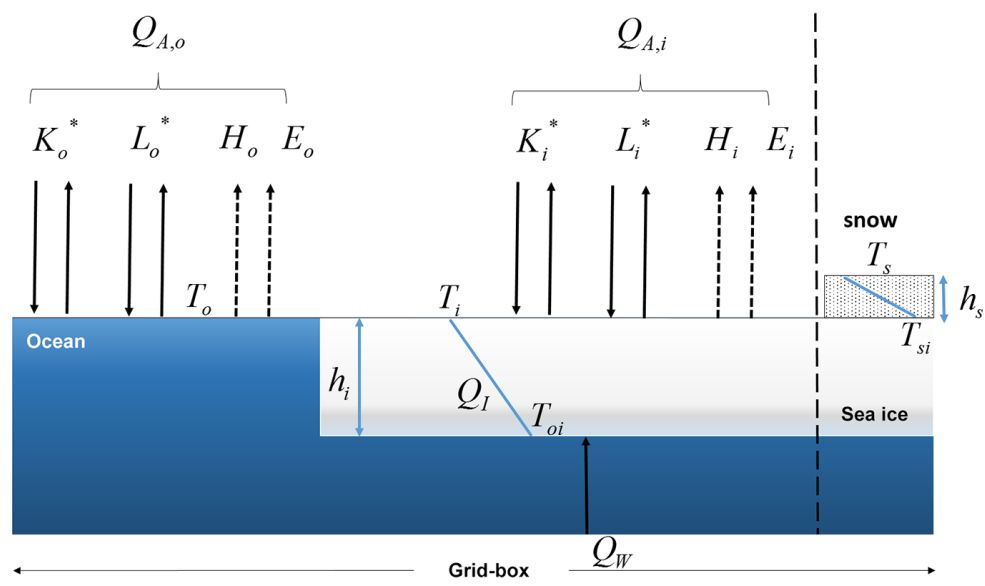

Figure 4. Scheme of the modified two-layer thermodynamic sea-ice module of Schröder et al. (2011), extended with a tile approach for fractional sea ice. Sea ice is distinguished as bare ice or as snow-covered ice (with $h_{\mathrm{s}}=0.1 \mathrm{~m}$ snow depth if sea-ice thickness $h_{\mathrm{i}}>0.2 \mathrm{~m}$ ). The subgrid-scale open ocean fraction is either ice free $(\mathrm{C} 05-10 / 0)$ or assumed to be covered with $1 \mathrm{~cm}(\mathrm{C} 05-10 / 1, \mathrm{C} 05-50 / 1), 5 \mathrm{~cm}(\mathrm{C} 05-$ $50 / 5)$, or $10 \mathrm{~cm}$ thin ice (C05-10/10). In the reference simulation (C05-ref), grid boxes with $0 \%$ sea-ice concentration are covered with $1 \mathrm{~cm}$ grid-scale thin ice. If the index $k$ denotes either sea ice $(i)$ or ocean $(o)$, then $Q_{\mathrm{A}, k}$ is the total atmospheric heat flux, $K_{k}^{*}$ is the net shortwave, and $L_{k}^{*}$ the net longwave radiation. $H_{k}$ and $E_{k}$ are the sensible and latent heat fluxes. $T_{k}$ is the surface temperature, $h_{\mathrm{i}}$ the ice thickness, $T_{\mathrm{oi}}$ the ice-ocean interface temperature, and $T_{\mathrm{si}}$ the snow-ice interface temperature. $Q_{\mathrm{I}}$ denotes the conductive heat flux through the ice and $Q_{\text {W }}$ the turbulent heat flux from the oceanic mixed layer into the ice.

C05-50/5 and C05-50/1 runs are motivated by the fact that the sea-ice cover in the marginal ice zone consists of thicker ice floes $(>20 \mathrm{~cm})$ (detected by microwave satellite sensors) and thin ice (here the assumed 5 or $1 \mathrm{~cm}$ ), which is not detected by microwave sensors. Thus we denote C05-50/1 as the simulation with "realistic" assumptions based on MODIS TIT.

Although this is a crude simplification to the real sea-ice thickness, it is suited for our purpose to investigate the impact on the magnitude of ice production and on the modification of the ABL. We intended to consider sea ice in a computational cheap approach that still incorporates realistic thermodynamical processes. For a more sophisticated approach, a full dynamic-thermodynamic sea-ice model needs to be coupled to CCLM.

\section{The two-layer thermodynamic sea-ice module}

\subsection{Basic module}

In this section the sea-ice module (Fig. 4) is briefly described. The module considers a snow and sea-ice layer and was described and originally implemented in the COSMO model by Schröder et al. (2011). It is based on the module of Mironov et al. (2012). For this study it is reimplemented within the version 5.0_clm1 of CCLM extended with the Køltzow seaice albedo scheme (see Appendix A). More important for this study is the implementation of a tile approach for the surface energy balance over fractional sea ice (see Appendix B). The module and hence sea-ice growth calculation is only ap- plied to grid boxes with an initial sea-ice cover. Formation of grease ice in open water is not parameterized in CCLM, which is a difficult task even for stand-alone sea-ice ocean models. Nevertheless, a more sophisticated parameterization has been recently developed by Smedsrud and Martin (2015). For this reason we calculated sea-ice production in a postprocessing step (see Sect. 3.4).

The module assumes a constant ocean/ice interface temperature of $T_{\mathrm{oi}}=-1.7^{\circ} \mathrm{C}$; i.e. $T_{\mathrm{oi}}$ is not dependent on salinity. A temperature of $-1.7^{\circ} \mathrm{C}$ assumes approximately a salinity of $31.1 \mathrm{psu}$. The module ignores turbulent heat fluxes from the ocean at the lower boundary. Heat conductivity parameters are $2.3 \mathrm{~W} \mathrm{~m}^{-1} \mathrm{~K}^{-1}$ for sea ice and $0.76 \mathrm{~W} \mathrm{~m}^{-1} \mathrm{~K}^{-1}$ for snow. The module assumes a snow cover of $h_{\mathrm{s}}=0.1 \mathrm{~m}$ if the ice thickness exceeds a threshold $h_{\mathrm{i}}>h_{\mathrm{c}}$ with $h_{\mathrm{c}}=0.2 \mathrm{~m}$.

\subsection{Sea-ice concentration and thickness for initial conditions}

SIC is prescribed from Advanced Microwave Scanning Radiometer - Earth Observing System (AMSR-E) data (Spreen et al., 2008), provided by the University of Bremen. The original data sets are available on a daily basis at a horizontal resolution of $6.25 \mathrm{~km}$. In order to use them for CCLM, we interpolated the SIC fields onto the $\mathrm{C} 15$ and $\mathrm{C} 05$ grid, respectively, by a bilinear approach for every simulation day. All grid boxes with SIC $\leq 70 \%$ are treated as polynyas (Massom et al., 1998; Adams et al., 2011; Preußer et al., 2015a). Realistic polynya areas are retrieved by using this threshold, as shown by Adams et al. (2011) in comparison to a polynya signature simulation method (Markus and Burns, 1995). 
SIT is taken from the PIOMAS data set (Zhang and Rothrock, 2003). The PIOMAS data are available on a daily basis with a mean grid spacing of about $25 \mathrm{~km}$ (Hines et al., 2015). These daily fields were masked with the daily SIC fields to obtain consistent sea-ice extents. Thereby sea ice outside the AMSR-E mask was removed and grid boxes which were ice free in the daily PIOMAS fields but covered with ice in the mask were assigned with an interpolated SIT from a nearest neighbour method.

Schweiger et al. (2011) state that PIOMAS seems to overestimate thin-ice thickness and underestimates thicker ice. Nevertheless, the overestimation should not be problematic in our application, since we have to set TIT for daily fields according to AMSR-E data. Underestimations of thicker ice is of minor concern to our study due to the focus on areas with thin ice. Using this setup, the sea-ice thickness fields are much more realistic than in previous studies, where a constant thickness of $1 \mathrm{~m}$ was assumed outside polynyas (Ebner et al., 2011; Schröder et al., 2011; Bauer et al., 2013).

\subsection{Polynya area}

In Fig. 5 daily polynya areas for the winter period 2007/2008 are shown. According to the AMSR-E data set, which has been used to prescribe the SIC in CCLM and in the COSMO simulations of Bauer et al. (2013), large polynya events $\left(>10^{4} \mathrm{~km}^{2}\right)$ occurred at the end of November, in January, and in March/April. The polynya areas of Willmes et al. (2011a) are approximately of the same order as those used for CCLM, whereas the retrieved polynya areas from MODIS2km are considerably larger. This discrepancy is caused by different threshold definitions for polynyas and by different horizontal resolutions. For the MODIS2km data, polynyas were defined as areas with thin ice, $\leq 20 \mathrm{~cm}$, as in Preußer et al. (2015b). Given that and the higher horizontal resolution it is likely that also leads within the polynya masks, not resolved by the microwave satellite data, are contributing to the total thin-ice area and hence larger areas result. If areas of open water outside polynyas are considered as well, then the potential area for ice production increases in CCLM up to the area derived from MODIS2km data, except in the period of late November to the middle of January, which remains lower. Another difference between the polynya area derived from CCLM and in particular the area from Willmes et al. (2011a) is that the latter nearly never drops to zero during this winter.

\subsection{Estimation of sea-ice production}

In accordance to previous model or satellite-based studies, IP was calculated in a post-processing step using the energy balance (Bauer et al., 2013; Ebner et al., 2011; Willmes et al., 2011a). This approach assumes that if the water within a polynya is at the freezing point, all energy loss to the atmosphere through the ocean surface is compensated by freezing.

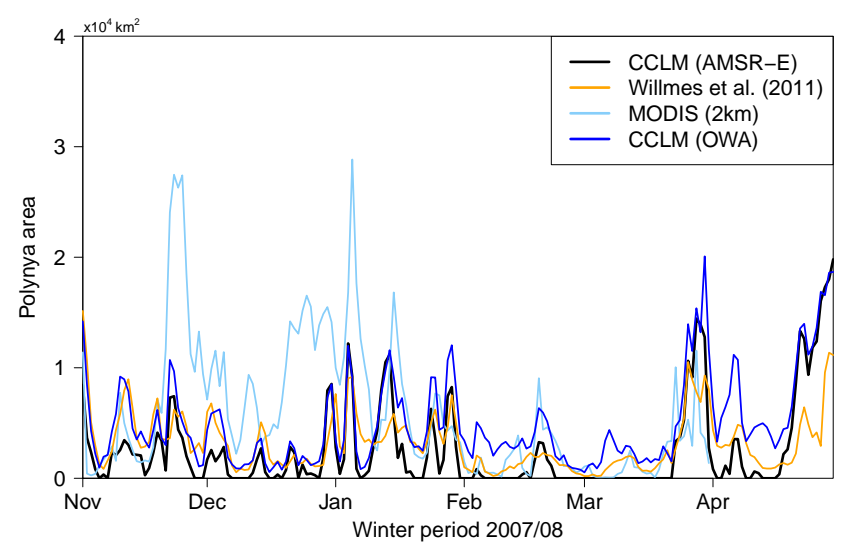

Figure 5. Total daily polynya area interpolated from AMSR-E (using a $70 \%$ threshold) onto the CCLM $5 \mathrm{~km}$ grid in the Laptev Sea for the winter period 2007/2008 aggregated for the four polynya masks. In addition, the polynya area plus open-water area $(\mathrm{OWA}=1-\mathrm{SIC})$ for the polynya masks is shown. Based on remote sensing the polynya areas estimated from Willmes et al. (2011a) and MODIS $2 \mathrm{~km}$ data are shown. The total area of the polynya masks is $26.19 \times 10^{4} \mathrm{~km}^{2}$.

Hence sea-ice growth only occurs if the total atmospheric energy flux over ice (index $k=i$ ) or ocean (index $k=o$ ) $Q_{\mathrm{A}, k}=K_{k}^{*}+L_{k}^{*}+H_{k}+E_{k}$ is negative, i.e. the ocean loses heat:

$$
\frac{\partial h_{\mathrm{i}}}{\partial t}=-\frac{Q_{\mathrm{A}, k}}{\rho_{\mathrm{i}} \cdot L_{\mathrm{f}}},
$$

with $h_{\mathrm{i}}$ the sea-ice thickness, $\rho_{\mathrm{i}}=910 \mathrm{~kg} \mathrm{~m}^{-3}$ the density of sea ice, and $L_{\mathrm{f}}=0.334 \times 10^{6} \mathrm{~J} \mathrm{~kg}^{-1}$ the latent heat of fusion. We restricted this estimation to the four polynya areas in the Laptev Sea (see Fig. 2), which are identical to those of Willmes et al. (2011a). Hence, direct comparisons of our results with estimations from remote sensing were possible.

We further calculated the IP using the MOD/MYD29 seaice surface temperature product (Hall et al., 2004; Riggs et al., 2006) derived from MODIS Terra and Aqua data. In combination with ERA-Interim data $(2 \mathrm{~m}$ temperature, $2 \mathrm{~m}$ dew point temperature, $10 \mathrm{~m}$ horizontal wind components, and pressure at mean sea level), an energy balance model (e.g. Yu and Lindsay, 2003; Adams et al., 2013; Preußer et al., 2015a, b) was applied to derive thin-ice thicknesses up to $0.2 \mathrm{~m}$ at a horizontal resolution of about $2 \mathrm{~km}$. We refer to this estimation as MODIS2km. The turbulent fluxes of sensible and latent heat were calculated by an iterative bulk approach (Launiainen and Vihma, 1990) based on the MoninObukhov similarity theory. Thereby, the turbulent exchange coefficient $C_{\mathrm{H}}$ is a function of stability and of the roughness length for momentum and for heat (Doms et al., 2011). Shortwave radiation is not considered as the method is restricted to night-time conditions during winter. This method is only applicable to clear-sky conditions, as clouds and fog impede an estimation of sea-ice surface temperature (Riggs et al., 
2006). Therefore the number of useful swaths per day is variable. For instance, in the Laptev Sea there are about 10 to 14 swaths per day (2002/2003 to 2014/2015 - NovemberMarch).

Cloud-induced gaps in our daily sea-ice surface temperature and thin-ice thickness composites were filled by a spatial feature reconstruction procedure (Paul et al., 2015; Preußer et al., 2015a). This method interpolates information of previous and subsequent days to fill gaps caused by cloud cover. Based on these corrected composites and using the method described in Preußer et al. (2015b), ice production rates were calculated for each pixel with an ice thickness $\leq 0.2 \mathrm{~m}$, i.e. for polynya areas.

In a sensitivity analysis of this method (without the spatial feature reconstruction), Adams et al. (2013) stated an uncertainty for the ice-thickness retrieval of $\pm 1.0, \pm 2.1$, and $\pm 5.3 \mathrm{~cm}$ for thin-ice classes of $0-5,5-10$, and $10-20 \mathrm{~cm}$, respectively. Therefore, we constrained our analysis to ice thicknesses $\leq 0.2 \mathrm{~m}$, as this range is regarded as sufficient to get reliable results for ice production (Yu and Rothrock, 1996; Adams et al., 2013).

Furthermore, we compared our results to the estimations of Willmes et al. (2011a). In their study they used a constant transfer coefficient for heat $C_{\mathrm{H}}=3 \times 10^{-3}$ to calculate $H$ and $E$ from AMSR-E data and using MODIS thin-ice distributions and National Centers for Environmental Prediction/National Center for Atmospheric Research $(\mathrm{NCEP} / \mathrm{NCAR})$ reanalysis data $\left(2.5^{\circ} \times 2.5^{\circ}\right)$ as atmospheric forcing for an energy balance model. However, we omitted the most western polynya mask of their study and compared the IP only to the four remaining masks shown in Figs. 1 and 2.

We also compared our IP estimations to model-based estimations of Bauer et al. (2013). Bauer et al. (2013) conducted two COSMO simulations at $5 \mathrm{~km}$ horizontal resolution (without a tile approach) for the same winter 2007/2008 in the Laptev Sea. One simulation assumed a grid-scale thin-ice thickness of $10 \mathrm{~cm}$ within polynyas (B10) and one simulation assumed open water (B00). Both simulations further assumed a sea-ice thickness of $1 \mathrm{~m}$ outside polynyas. Both simulations were forced by a $15 \mathrm{~km}$ COSMO simulation, which was nested within the output of the global GME model.

\section{Evaluation with in situ data}

The model output of the reference and the five sensitivity simulations were first evaluated with in situ data. During the Transdrift XIII-2 expedition from 11 to 29 April 2008 four automatic weather stations (AWS, Table 2) were deployed on the fast ice of WNS (see Fig. 2) (Heinemann et al., 2010). The AWS measured wind speed and direction at $3 \mathrm{~m}$ height with an accuracy of $2 \%$ in speed and $3^{\circ}$ in direction, air temperature and relative humidity at $2 \mathrm{~m}$ height with and accuracy of $0.5 \mathrm{~K}$ and $4 \%$, and pressure with an accuracy of
Table 2. Overview of the four automatic weather stations (AWS) with hourly measurements which were deployed during the Transdrift XIII-2 expedition from 11 to 29 April 2008 (Heinemann et al., 2010). See the location of the AWS in Fig. 2.

\begin{tabular}{lll}
\hline Station & Location & Measured period (UTC) \\
\hline AWS1 & $128.16^{\circ} \mathrm{E}$ & 11 Apr 2008 07:00-26 Apr 2008 12:00 \\
& $73.80^{\circ} \mathrm{N}$ & \\
AWS2 & $129.32^{\circ} \mathrm{E}$ & 12 Apr 2008 04:00-29 Apr 2008 03:00 \\
& $74.39^{\circ} \mathrm{N}$ & \\
AWS3 & $131.25^{\circ} \mathrm{E}$ & 14 Apr 2008 06:00-29 Apr 2008 01:00 \\
& $74.67^{\circ} \mathrm{N}$ & \\
AWS4 & $128.61^{\circ} \mathrm{E}$ & 24 Apr 2008 06:00-28 Apr 2008 02:00 \\
& $74.05^{\circ} \mathrm{N}$ & \\
\hline
\end{tabular}

$1 \mathrm{hPa}$. Furthermore, net radiation was measured by a net radiometer with an accuracy of $5 \mathrm{~W} \mathrm{~m}^{-2}$.

Here, we compared hourly C05 data with the AWS data. In order to judge whether the simulations deviate significantly from the AWS data two-sided $t$ tests were performed $(\alpha=95 \%)$. The statistical comparisons were only performed for data pairs without missing values and only for days when the SIC was $>95 \%$. This limitation is necessary because the time series of CCLM represent spatial averages of a grid box, whereas the AWS time series are point data on a solid ice cover. If the SIC of CCLM is $<100 \%$ then the grid average automatically differs from the station time series, which always represent conditions at $100 \%$ SIC.

Table 3 shows the results for the reference simulation (C05-ref) and two sensitivity simulations: C05-10/0 (subgrid-scale open water) and C05-50/1 (realistic assumptions). In the remainder of the paper, we concentrate on the comparison of these three simulations. Since the comparison was made only over a solid sea-ice cover, the other simulations showed very similar results (not shown).

In general, the inter-model differences are minor for all variables. The comparison for the $2 \mathrm{~m}$ temperature shows that the $\mathrm{C} 05$ simulations are generally able to reproduce the observed temperatures during the measurement period. The temporal correlation is about $r=0.8$, except for the comparison with AWS4. The bias is about $-1{ }^{\circ} \mathrm{C}$ for AWS2-3, less for AWS1, and about $-3^{\circ} \mathrm{C}$ for AWS4. Except for the latter, C05 underestimates the variability of the $2 \mathrm{~m}$ temperature. This might be caused by the assumptions made on snow properties in $\mathrm{C} 05$. Although the $t$ tests are significant for differences of about $1{ }^{\circ} \mathrm{C}$, this difference is sufficient for our analysis keeping in mind that grid-box averages were compared with point data.

In case of wind speed there is a good agreement $(r \geq 0.7)$, although we compared $10 \mathrm{~m}$ wind speed of CCLM with measurements at $3 \mathrm{~m}$ height. The mean and standard variance are both in accordance with the AWS data, although significant for differences $\geq 0.4 \mathrm{~m} \mathrm{~s}^{-1}$. Inversely, this agreement implies that CCLM underestimates wind speeds at $10 \mathrm{~m}$, although we 
Table 3. Statistical comparison of $2 \mathrm{~m}$ temperature, $10 \mathrm{~m}$ wind speed ( $3 \mathrm{~m}$ in case of the AWS), and net radiation $\left(K^{*}+L^{*}\right)$ of the four AWS and the C05 simulations: C05-ref (reference), C05-10/0 (open water), and C05-50/1 (realistic). Hourly means are denoted by $\bar{x}$ and standard deviations are denoted by $\sigma$. The Pearson correlation coefficient $(r)$ was calculated with the AWS and C05 time series. The critical correlation coefficient $(\alpha=5 \%)$, which depend on the sample size of the AWS time series, is between 0.1 and 0.2 . In addition, the resulting $p$ values $(p)$ of two-sided $t$ tests $(\alpha=5 \%)$ are shown. Significant differences are marked with *. Data pairs with missing values in the AWS data or where the sea-ice concentration is $<95 \%$ were removed prior to the analyses.

\begin{tabular}{|c|c|c|c|c|c|c|c|c|c|c|c|c|}
\hline \multirow[t]{2}{*}{ Data } & \multicolumn{4}{|c|}{$2 \mathrm{~m}$ temperature $\left({ }^{\circ} \mathrm{C}\right)$} & \multicolumn{4}{|c|}{$10 \mathrm{~m}$ wind speed $\left(\mathrm{m} \mathrm{s}^{-1}\right)$} & \multicolumn{4}{|c|}{ Net radiation $\left(\mathrm{W} \mathrm{m}^{-2}\right)$} \\
\hline & $\bar{x}$ & $\sigma$ & $r$ & $p$ & $\bar{x}$ & $\sigma$ & $r$ & $p$ & $\bar{x}$ & $\sigma$ & $r$ & $p$ \\
\hline AWS1 & -20.44 & 3.24 & - & - & 3.38 & 1.55 & - & - & -17.87 & 31.70 & - & - \\
\hline C05-ref & -20.49 & 1.95 & 0.80 & 0.83 & 3.41 & 1.57 & 0.75 & 0.83 & -30.21 & 26.01 & 0.79 & $<0.01^{*}$ \\
\hline $\mathrm{C} 05-10 / 0$ & -20.52 & 1.92 & 0.79 & 0.73 & 3.48 & 1.58 & 0.75 & 0.48 & -30.36 & 26.22 & 0.81 & $<0.01^{*}$ \\
\hline $\mathrm{C} 05-50 / 1$ & -20.53 & 1.92 & 0.79 & 0.68 & 3.46 & 1.59 & 0.75 & 0.56 & -29.90 & 26.35 & 0.80 & $<0.01^{*}$ \\
\hline AWS2 & -19.50 & 3.50 & - & - & 2.63 & 1.33 & - & - & -10.37 & 37.23 & - & - \\
\hline C05-ref & -20.40 & 2.23 & 0.80 & $<0.01^{*}$ & 3.33 & 1.31 & 0.69 & $<0.01^{*}$ & -28.61 & 24.32 & 0.73 & $<0.01^{*}$ \\
\hline C05-10/0 & -20.47 & 2.13 & 0.78 & $<0.01^{*}$ & 3.36 & 1.36 & 0.68 & $<0.01^{*}$ & -28.70 & 25.33 & 0.75 & $<0.01^{*}$ \\
\hline C05-50/1 & -20.49 & 2.13 & 0.78 & $<0.01^{*}$ & 3.36 & 1.35 & 0.69 & $<0.01^{*}$ & -28.54 & 25.13 & 0.75 & $<0.01^{*}$ \\
\hline AWS3 & -18.91 & 5.57 & - & - & 2.75 & 1.58 & - & - & -11.76 & 30.28 & - & - \\
\hline C05-ref & -19.38 & 3.07 & 0.85 & 0.20 & 3.17 & 1.48 & 0.70 & $<0.01^{*}$ & -24.20 & 27.34 & 0.67 & $<0.01^{*}$ \\
\hline C05-10/0 & -19.44 & 3.10 & 0.87 & 0.15 & 3.17 & 1.46 & 0.69 & $<0.01^{*}$ & -23.39 & 28.95 & 0.69 & $<0.01^{*}$ \\
\hline C05-50/1 & -19.48 & 3.08 & 0.86 & 0.12 & 3.17 & 1.46 & 0.70 & $<0.01^{*}$ & -23.46 & 28.93 & 0.70 & $<0.01^{*}$ \\
\hline AWS4 & -13.36 & 2.29 & - & - & 4.17 & 1.99 & - & - & -13.80 & 26.17 & - & - \\
\hline C05-ref & -16.17 & 3.29 & 0.67 & $<0.01^{*}$ & 4.67 & 2.36 & 0.91 & 0.12 & -35.55 & 27.63 & 0.70 & $<0.01^{*}$ \\
\hline C05-10/0 & -16.22 & 3.25 & 0.66 & $<0.01^{*}$ & 4.75 & 2.40 & 0.91 & 0.07 & -34.26 & 28.51 & 0.74 & $<0.01^{*}$ \\
\hline C05-50/1 & -16.24 & 3.28 & 0.65 & $<0.01^{*}$ & 4.65 & 2.29 & 0.92 & 0.13 & -34.25 & 28.51 & 0.73 & $<0.01^{*}$ \\
\hline
\end{tabular}

do not have reference data at $10 \mathrm{~m}$ for a evaluation. Significant differences were found for the comparison of the net radiation. Although the temporal correlation is high $(r \geq 0.7)$, the mean of $\mathrm{C} 05$ is about $13-22 \mathrm{~W} \mathrm{~m}^{-2}$ lower than observed, meaning a slightly too-high heat flux through the sea-ice cover. This difference might be caused by the assumption on the sea-ice properties (e.g. a constant temperature at the iceocean interface) or by the slight cold bias of the ABL above the sea ice.

Albeit some deviations CCLM is able to reproduce the basic conditions of the near-surface variables during this period with our chosen configurations. However, the reasons for these deviations need further investigation with longer time series.

\section{Effects of the tile approach on the atmospheric boundary layer}

\subsection{Case study on 4 January 2008}

The effects of the TA are exemplified for a case study on 4 January 2008. On this day a low was located over the Taimyr peninsula in the western Laptev Sea. The large pressure gradient generated strong, prevailing off-shore winds, which caused a large opening of polynyas at the fast-ice edge in the Laptev Sea (Fig. 6). The $10 \mathrm{~m}$ wind speed reached 10 to
$15 \mathrm{~m} \mathrm{~s}^{-1}$ and was blowing offshore over the AL. The associated sea-ice concentrations for that day are shown in Fig. 2. Within polynyas, the SIC is between 0 and $70 \%$.

\subsubsection{Surface temperature}

The surface temperatures $\left(T_{\mathrm{sfc}}\right)$ of the $\mathrm{C} 05$ simulations at 15:00 UTC (Fig. 6) show a clear signal of the polynyas. Within the AL polynya the surface temperatures are -22 to $-24{ }^{\circ} \mathrm{C}$ in C05-ref (Fig. 6a), which is +6 to $+16^{\circ} \mathrm{C}$ warmer than the surrounding fast and pack ice.

Furthermore, $T_{\text {sfc }}$ is about $+2{ }^{\circ} \mathrm{C}$ warmer at the downwind side than at the windward side. This is, however, not realistic compared to nature. One would expect higher temperatures at the windward side due to the spatial gradient of the thin ice with the thinnest or even open water at the windward side. Since in C05-ref a homogeneous thin-ice thickness of $10 \mathrm{~cm}$ is assumed within the polynya, this effect is not represented in the simulation.

Much higher surface temperatures were simulated by all sensitivity simulations. As an upper limit, C05-10/0 simulates $>10{ }^{\circ} \mathrm{C}$ higher surface temperatures. This increase of surface temperature is in accordance with results of Bromwich et al. (2009), who found an increase of $14^{\circ} \mathrm{C}$ for sea-ice concentrations of about $60 \%$ in winter. In the more realistic configuration of C05-50/1 temperatures are about $\leq 10^{\circ} \mathrm{C}$ warmer. The warmest areas within the polynya tend 

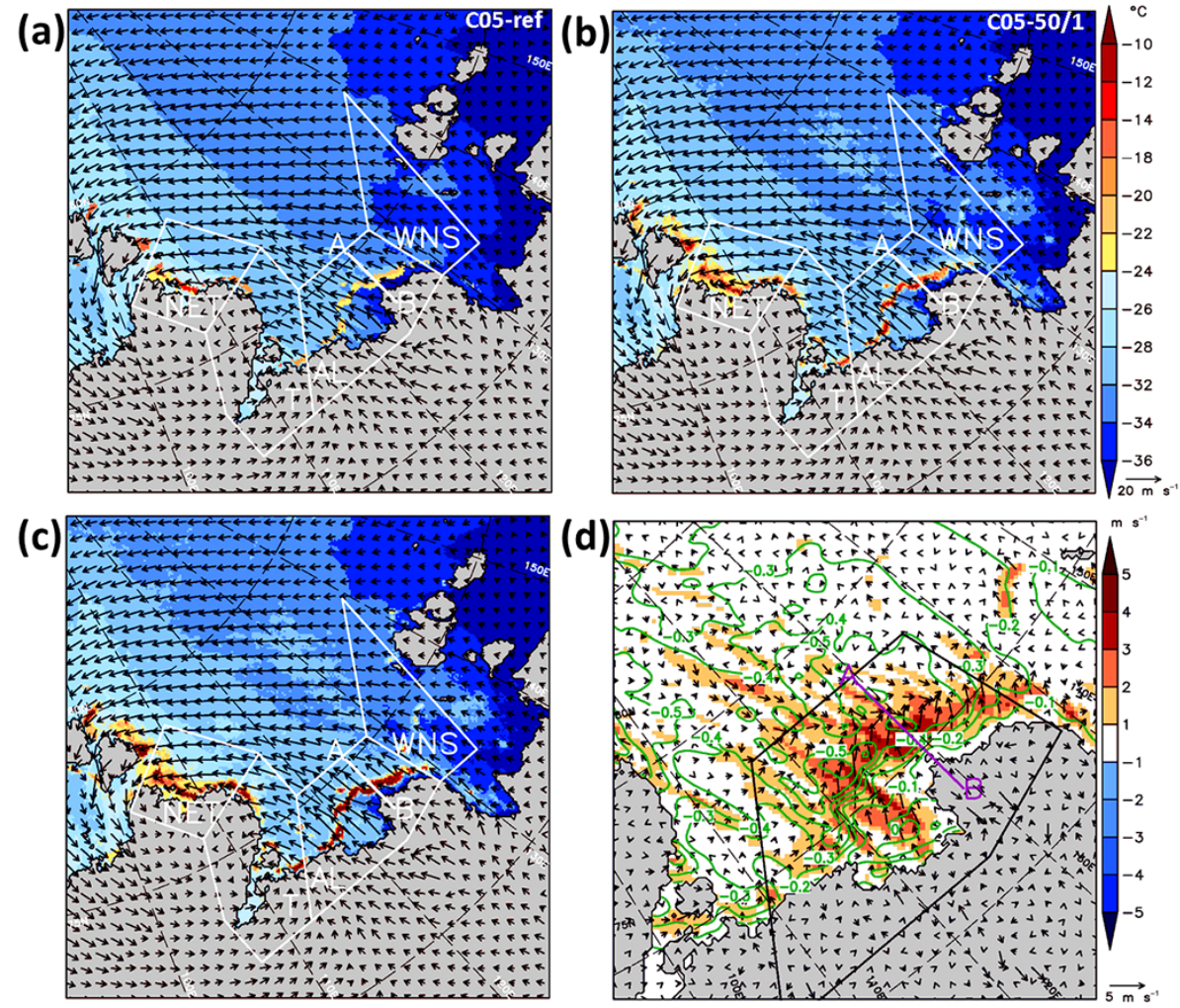

Figure 6. Surface temperature and $10 \mathrm{~m}$ wind field on 4 January 2008 at 15:00 UTC in (a) C05-ref (reference), (b) C05-50/1 (realistic), and (c) C05-10/0 (open water). In (d) anomalies (C05-10/0 minus C05-ref) over the AL polynya are shown for wind vectors (note different scale) and wind magnitude (colour shaded) at $10 \mathrm{~m}$ height and for pressure at mean sea level (green contour lines). The white line in (a) to (c) (magenta in $\mathbf{d}$ ) marks the cross section $\mathrm{A} \rightarrow \mathrm{B}$ used for Fig. 7.

to be at the windward side now, which is owed to the TA and the thereby considered spatial thin-ice gradient. Another effect, which becomes visible, is that the marginal area of the polynyas with warmer $T_{\mathrm{sfc}}$ increases with the use of TA. This effect is most obvious for the NET polynyas. This increases the area where heat is transferred from the ocean into the atmosphere and causes smooth transitions from the fast or pack ice to the polynyas. An increased heat loss has to be balanced by an increase in frazil ice production.

\subsection{2 $10 \mathrm{~m}$ wind speed}

The wind speed is the main driver for mixing in the ABL above polynyas and mainly controls the sensitive heat flux until the warming of the ABL reduces the vertical temperature gradient and thus the sensitive heat loss and subsequently the ice production. Figure 6 shows the $10 \mathrm{~m}$ wind speed and direction on 4 January 2008 at 15:00 UTC. In the reference run (C05-ref) the wind speed above the AL polynya is about 14 to $18 \mathrm{~m} \mathrm{~s}^{-1}$. The wind speed slightly increases (Fig. 6d) in the sensitivity simulations $\left(+2\right.$ to $\left.+5 \mathrm{~m} \mathrm{~s}^{-1}\right)$. This increase is caused by increased pressure gradients in the vicinity of the AL polynya which develop as the convection above the polynya lowers the local surface pressure by up to $-0.5 \mathrm{hPa}$. Furthermore, the pressure anomaly is orientated alongside the polynya, resulting in slightly more anticyclonic wind directions. This increase of near-surface wind speed is in agreement with results from idealized studies conducted by Ebner et al. (2011) (see Fig. 5c therein). Ebner et al. (2011) concluded that the increase in wind speed results in an increased net ice production, despite an increased boundary layer warming. The increase in near-surface wind speed causes a larger momentum flux (not shown, but see Sect. 5.1.3 for the TKE) and higher energy loss from the ocean. Furthermore, although not represented in the present CCLM model, higher wind speeds increase the sea-ice drift within polynyas, so that newly formed ice is likely to drift faster and a strong heat loss is maintained. Both processes are expected to increase the IP. However, the latter issue has to be investigated by coupled atmosphere-sea-ice-ocean model simulations.

\subsubsection{Vertical cross sections}

Figure 7 shows vertical cross sections of the potential temperature $\Theta$, the horizontal and vertical wind speed, the cloud area fraction, and the TKE over the AL polynya. In C05-ref (Fig. 7a) $\Theta$ is about $-29^{\circ} \mathrm{C}$ at $10 \mathrm{~m}$ height over the polynya, 
about $-30^{\circ} \mathrm{C}$ about the pack ice, and colder than $-31^{\circ} \mathrm{C}$ over the fast ice. The boundary layer is stably stratified over the pack and the fast ice but over the polynya a well-mixed convective boundary layer (CBL) has developed, capped by an inversion at approximately 300 to $500 \mathrm{~m}$ height. Comparing the cross sections for the three shown model configurations, it becomes obvious that the assumptions on the thin ice within a polynya have considerable effects on the ABL.

As mentioned earlier, the onset of the CBL at the windward polynya edge is displaced to the polynya interior in the reference simulation (C05-ref) compared to the sensitivity simulations. This is due to the too thick ice in this area, preventing a large enough heat transfer and hence vertical mixing. This is also reflected in the low values of TKE compared to twice as high values for the sensitivity runs. In the open-water configuration (C05-10/0) the CBL is thus about $3{ }^{\circ} \mathrm{C}$ warmer than in the reference run. The warm air spreads as a plume downstream the polynya and can be tracked several hundred kilometres over the pack ice (not shown).

One might suspect that the warmer CBL of the sensitivity simulations might lead to a reduced vertical temperature gradient over the polynya and thus to a negative feedback for the surface sensible heat flux and thus ice production. This is not the case, since the surface temperature in areas with fractional ice cover is also warmer by about 6 to $16^{\circ} \mathrm{C}$, so that the vertical gradient remains or even increases. Secondly, the wind speed in the sensitivity runs is increased over the polynya due to increased local pressure gradients and thus enhances the turbulent fluxes. The increased sensible heat flux causes also TKE production by buoyancy.

Almost all sensitivity simulations show considerably less cloud formation above and downstream the polynya compared to the reference simulation. Although the amount and location of clouds vary, the clouds almost vanish. The reason for this is that the maximum value of the specific humidity is about $0.4 \times 10^{-3} \mathrm{~kg} \mathrm{~kg}^{-1}$ over the AL polynya in all simulations, and if the CBL warms the condensation of water vapour is inhibited. As a result, nearly no clouds form above the polynya.

\subsubsection{Total atmospheric energy flux}

The above-mentioned findings result in an increased heat loss from the ocean, which is confirmed and shown in Fig. 8. In the reference simulation the total atmospheric heat flux $\left(Q_{\mathrm{A}}\right)$ is, almost homogeneously, about $-500 \mathrm{~W} \mathrm{~m}^{-2}$ over the $\mathrm{AL}$ polynya (note that the negative sign denotes upward fluxes). By assuming subgrid-scale open water the heat loss considerably increases, exceeding $-1000 \mathrm{~W} \mathrm{~m}^{-2}$ at the windward edge and in the centre of the polynya. Higher and more structured values of $Q_{\mathrm{A}}$ resulted also from C05-50/1. The smooth transition at the polynya margins is also visible from this figure. Since we based the estimation of ice production on this quantity it is clear that there will be considerable differences as well.
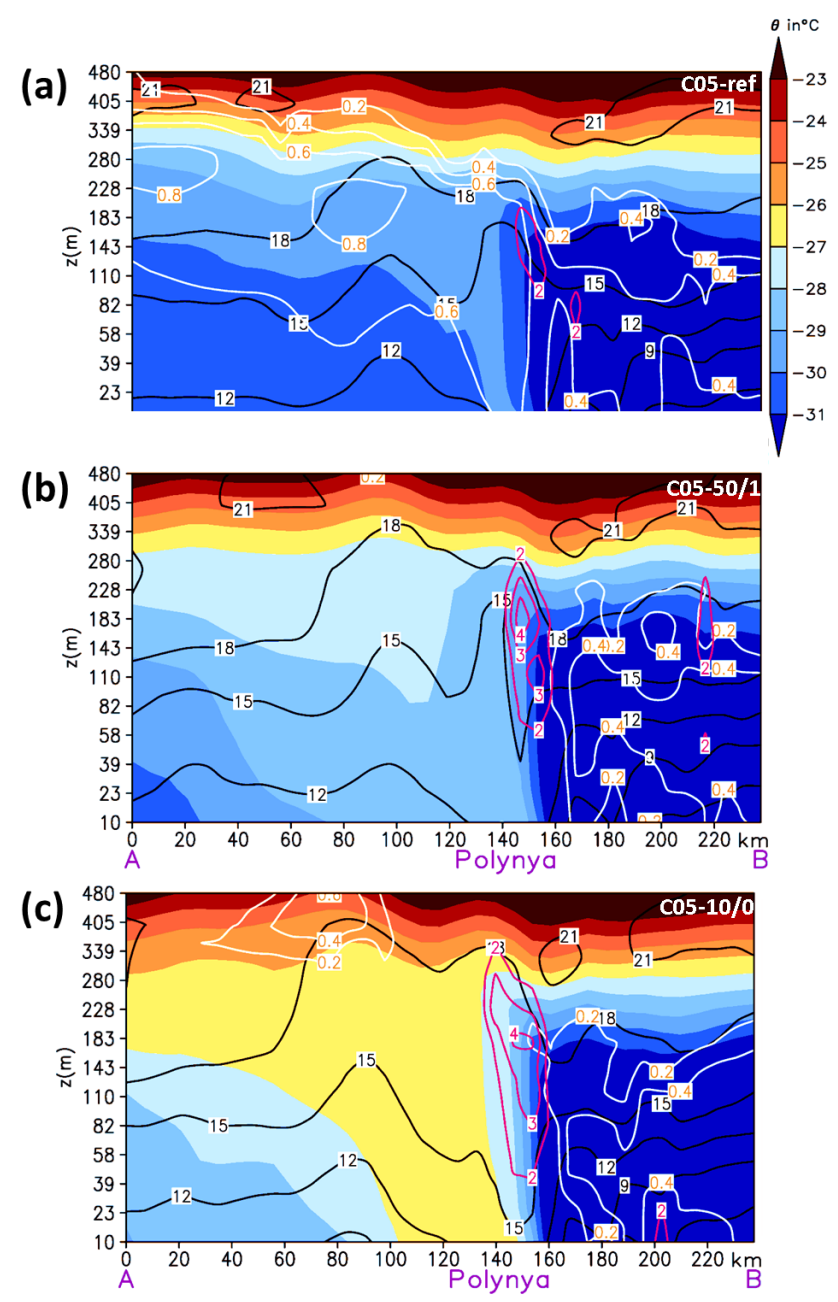

Figure 7. Vertical cross sections of the potential temperature $\Theta$, horizontal wind speed (black contour lines), turbulent kinetic energy (TKE in $\mathrm{m}^{2} \mathrm{~s}^{-2}$, magenta contour lines), and cloud fraction (white contour lines and orange labels) on 4 January 2008 at 15:00 UTC for (a) C05-ref (reference), (b) C05-50/1 (realistic), and (c) C05-10/0 (open water). The horizontal distance is about $240 \mathrm{~km}$ and the location of the cross section A (pack ice) $\rightarrow$ B (fast ice) is shown in Fig. 2.

\subsection{Energy balance components for the winter period 2007/2008}

In this section we analyse how the assumptions on subgridscale thin ice within the tile approach affects the energy balance at the surface over the whole winter season 2007/2008. We compared daily means of the components of total atmospheric heat fluxes, which were spatially averaged over polynyas (Fig. 9). Thereby, at least nine grid boxes within the polynya masks have to had a SIC $\leq 70 \%$ in order to be considered in the analysis. 

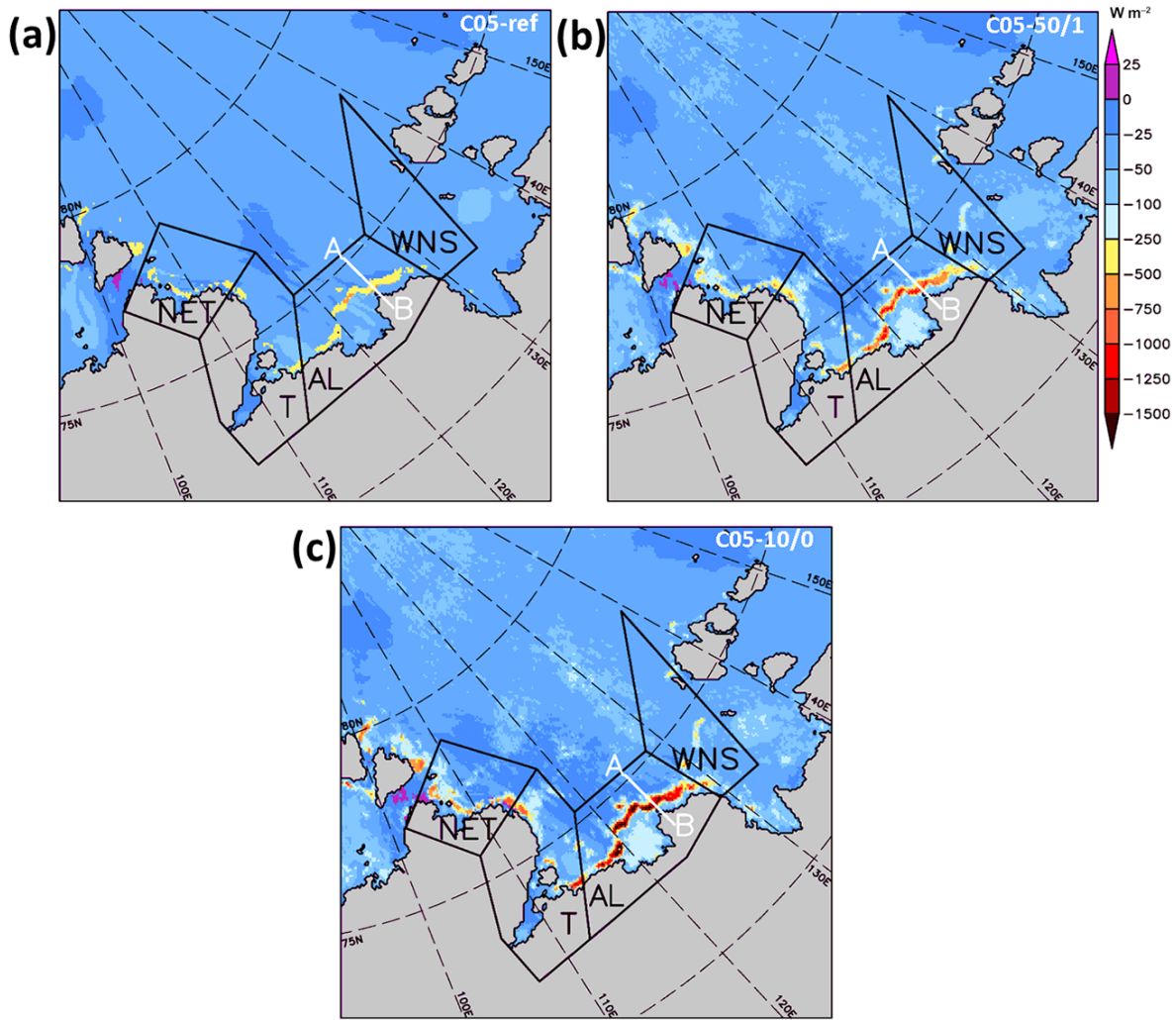

Figure 8. Total atmospheric energy flux on 4 January 2008 at 15:00 UTC in (a) C05-ref (reference), (b) C05-50/1 (realistic), and (c) C05-10/0 (open water). Negative fluxes are directed upwards. The white line marks the cross section $\mathrm{A} \rightarrow \mathrm{B}$ used for Fig. 7.

In principle, the processes presented in Sect. 5.1 come into effect whenever a polynya is present. Thus, if the tile approach is used, $Q_{\mathrm{A}}$ is always more negative due to the consideration of subgrid-scale energy fluxes (Fig. 9) and more energy or heat is lost from the ocean. In the reference simulation (C05-ref) about $-253 \mathrm{~W} \mathrm{~m}^{-2}$ is lost on average within polynyas. If the subgrid-scale thin ice is reduced or replaced by open water then $Q_{\mathrm{A}}$ is much higher, reaching about $-529 \mathrm{~W} \mathrm{~m}^{-2}$ in the latter, which is about $+110 \%$. In the simulation with a realistic configuration (C05-50/1) the increase is about $+20 \%$, reaching about $-303 \mathrm{~W} \mathrm{~m}^{-2}$ on average.

The largest contribution to $Q_{\mathrm{A}}$ constitutes the sensible heat flux $H$ (Fig. 9). About $66 \%$ of the heat is lost via $H$ in the reference simulation, which slightly decreases to 57 to $65.6 \%$ if the tile approach is used. The strongest impact on the sensible heat flux shows C05-10/0. Here, $H$ doubles from $167 \mathrm{~W} \mathrm{~m}^{-2}$ in $\mathrm{C} 05$-ref to $-325 \mathrm{~W} \mathrm{~m}^{-2}$ due to the absence of the isolating sea-ice cover. The increase is less in the other sensitivity simulations, e.g. $+7.1 \%$ in the case of C05-50/1.

The other components contribute much less to the heat loss. However, the Bowen ratio (Bowen, 1926), which is the ratio $H / E$, reduces from about 4.0 (C05-ref) to 2.5 (C05$50 / 1)$ and $2.3(\mathrm{C} 05-10 / 0)$. The latent heat flux $(E)$ nearly

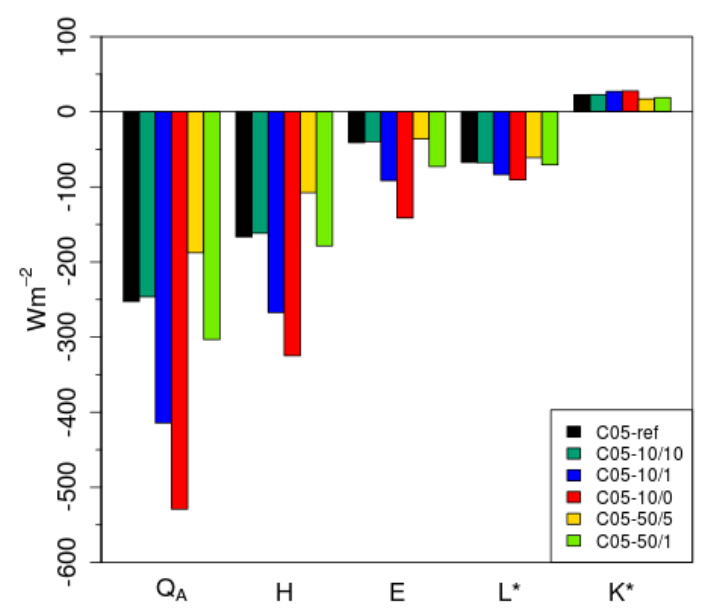

Figure 9. Temporal means of the energy balance $Q_{A}$ and its components ( $H$ is sensible heat flux, $E$ is latent heat flux, $L^{*}$ is net longwave, and $K^{*}$ net shortwave radiation) averaged over polynya grid boxes for the winter period 2007/2008. For the averaging at least nine grid boxes in the model domain had to be polynyas to include them in the calculation. 
Table 4. Total sea-ice production (IP) $\left(\mathrm{km}^{3}\right)$ in the winter period 2007/2008, aggregated over polynyas within the four polynya masks (Fig. 2). The daily mean $(\bar{x})$ and standard deviation $(\sigma)$ are given in $\mathrm{km}^{3} \mathrm{day}^{-1}$. The Pearson correlation coefficient $(r)$ was calculated with the IP time series and the estimates of Willmes et al. (2011a). The 95\% confidence interval (CI) of $r$ was calculated based on the Fisher

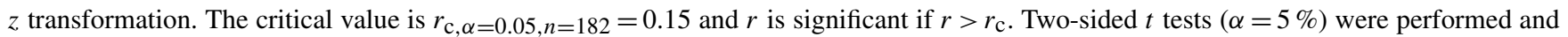
the resulting $p$ values $(p)$ are given. Significant differences are marked with ${ }^{*}$. The results from Bauer et al. (2013) assumed an ice thickness of $10 \mathrm{~cm}$ (B10) or open water (B00) within polynyas, both without a tile approach.

\begin{tabular}{lrrrrr}
\hline Data & Total & $\bar{x}$ & $\sigma$ & $r[95 \% \mathrm{CI}]$ & $p$ \\
\hline C05-ref & 29.1 & 0.2 & 0.2 & $0.65[0.56 ; 0.73]$ & 0.30 \\
C05-10/10 & 29.2 & 0.2 & 0.3 & $0.63[0.53 ; 0.71]$ & 0.34 \\
C05-10/1 & 49.3 & 0.3 & 0.4 & $0.63[0.53 ; 0.71]$ & $0.01^{*}$ \\
C05-10/0 & 65.2 & 0.4 & 0.6 & $0.61[0.51 ; 0.69]$ & $<0.01^{*}$ \\
C05-50/5 & 25.3 & 0.1 & 0.3 & $0.56[0.45 ; 0.65]$ & $0.05^{*}$ \\
C05-50/1 & 38.3 & 0.2 & 0.3 & $0.60[0.50 ; 0.69]$ & 0.30 \\
\hline Willmes et al. (2011a) $^{\text {a }}$ & 33.0 & 0.2 & 0.2 & - & - \\
MODIS2km & $49.1^{\mathrm{a}}$ & $0.3^{\mathrm{a}}$ & $0.4^{\mathrm{a}}$ & $0.45[0.33 ; 0.56]^{\mathrm{a}}$ & $<0.01^{*, \mathrm{~b}}$ \\
B10 & 25.4 & 0.1 & 0.2 & $0.67[0.58 ; 0.74]$ & $0.02^{*}$ \\
B00 & 45.5 & 0.3 & 0.4 & $0.68[0.59 ; 0.75]$ & $0.03^{*}$ \\
\hline
\end{tabular}

${ }^{a}$ Only for November-March; ${ }^{b}$ comparisons with Willmes et al. (2011a) were made only for November-March.

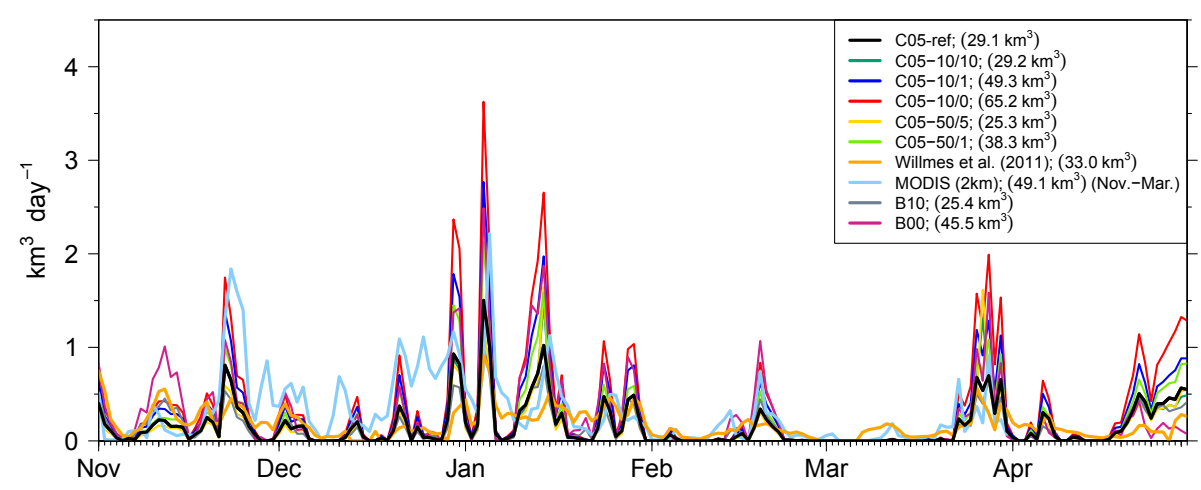

Figure 10. Daily sea-ice production within the Laptev Sea polynyas in the winter period 2007/2008, aggregated within the four polynya masks (only considering polynyas $>277 \mathrm{~km}^{2}$ in the C05 and Bauer et al., 2013, simulations - B10, B00). The total sea-ice production is given in parentheses in the legend (see also Table 4).

doubles for C05-50/1 compared to C05-ref, which is caused on one hand by the increase of the vertical gradient of specific humidity and on the other hand by the increase of the near-surface wind speed and TKE, enhancing the turbulence above the polynyas. Shortwave radiation $K^{*}$ only becomes important in the time from March until April, when the melting season begins. Therefore, $K^{*}$ is small compared to the other terms.

\section{Effects on sea-ice production in the winter period 2007/2008}

The daily sea-ice production rates were calculated for the individual polynyas as described in Sect. 3.4. Here we compared the ice production of the $\mathrm{C} 05$ simulations to the remote sensing estimations of Willmes et al. (2011a), to esti- mates based on MODIS2km (Sect. 3.4), and to model results of Bauer et al. (2013).

The time series of daily IP $\left(\mathrm{km}^{3} \mathrm{day}^{-1}\right)$ are shown in Fig. 10 and the total ice production for the whole winter are shown in Table 4. The total IP in the winter 2007/2008 is about $29.1 \mathrm{~km}^{3}$ in the reference simulation (C05-ref), which is not significantly different from the $33.0 \mathrm{~km}^{3}$ estimated by Willmes et al. (2011a). The temporal correlation is $r=0.65$, which is sufficiently high, but some differences are visible (Fig. 10). This result agrees well with the remote sensing estimates, although Willmes et al. (2011a) used a constant $C_{\mathrm{H}}$ for calculating the heat fluxes and much coarser atmospheric data.

The strongest, significant increase $(p<0.01)$ in IP was estimated from C05-10/0 with $65.2 \mathrm{~km}^{3}(+125 \%)$, where subgrid-scale open water was assumed. For realistic as- 

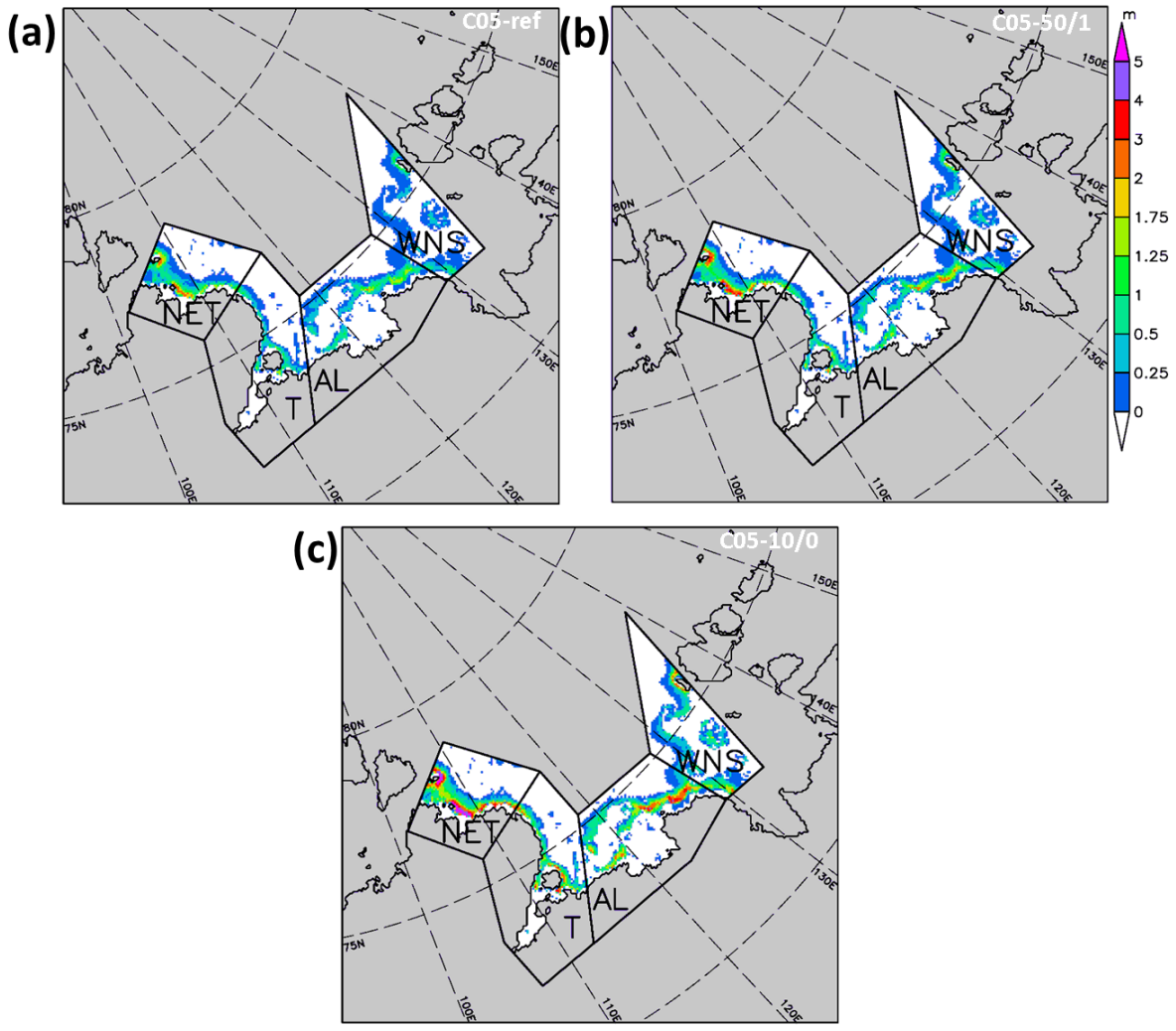

Figure 11. Total sea-ice production (m) within the Laptev Sea polynyas in the winter period 2007/2008 simulated by (a) C05-ref (reference), (b) C05-50/1 (realistic), and (c) C05-10/0 (open water).

sumptions (C05-50/1) the IP increases to $38.3 \mathrm{~km}^{3}$ (+39\%), which is not significant at the $95 \%$ level. The increase of IP is caused by the higher heat fluxes from the ocean into the overlying atmosphere as presented above. Compared to the results based on MODIS2km, where we estimated about $49.1 \mathrm{~km}^{3}$ due to the large polynya area, most of the simulations produced much less ice. Exceptions are C05-10/0 and C05-10/1, which reach or even exceed this estimate. These results show that there are large differences not only between the models but also between remote sensing approaches. For instance, the time of polynya openings and IP also differ $(r=0.45)$. Although such high IP could be reproduced in the Laptev Sea, the question remains of which remote sensing data set should be used for calibrating the models.

The IP based on an older reference COSMO simulation by Bauer et al. (2013) with $10 \mathrm{~cm}$ ice within polynyas (B10) is slightly less compared to our reference run (C05-ref), but significantly lower compared to Willmes et al. (2011a). Although the open-water sensitivity run of Bauer et al. (2013) (B00) produces higher IP, it is considerably less compared to our C05-10/0 run. B10 and B00 show a slightly higher correlation with the IP time series of Willmes et al. (2011a). The differences of B10/B00 with respect to our C05 simulations can be explained by differences in the model version, configuration, and nesting chain (GME vs. ERA-
Interim, different model domains). However, we cannot quantify the individual contributions to the deviations. All C05 sensitivity simulations show a higher daily standard deviation compared to the data from Willmes et al. (2011a), which increases with decreasing subgrid-scale thin ice. This is logical, because if a polynya opens then more heat is released compared to the reference simulation and thus the IP is higher.

Spatial maps of the total IP within polynyas in the winter 2007/2008 are shown in Fig. 11. In all simulations the highest IP occurs in the NET polynyas, with rates $>2 \mathrm{~m} /$ winter in C05-ref and $>5 \mathrm{~m} /$ winter in C05-10/0. Further, with considering the subgrid-scale thin ice or open water the spatial gradient of ice production is much better represented, with higher rates at the windward edge of the polynyas. Overall, we think that the assumptions made in C05-50/1 are realistic. Although we are aware that openwater areas may occur at the windward site of polynyas, the area of open water is much smaller compared to the entire polynya area (see Fig. 3). Thus, the heat flux and IP would be overestimated if open water were assumed in every grid box with fractional sea ice. 


\section{Discussion}

The simulation results of our study showed that there is a high sensitivity of the ice production to the assumptions on subgrid-scale thin-ice distribution, with considerable effects on the atmospheric boundary layer. The ABL receives more heat the thinner the ice is and warmed by up to $+3{ }^{\circ} \mathrm{C}$ in our subgrid-scale open-water configuration. However, the warmer ABL did not prevent further heat release from the ocean due to a weakened vertical temperature gradient. The simulations showed that the vertical temperature gradients remain or even exceed the gradients of the reference simulations. Two effects are responsible for this: (i) as the ice becomes thinner the surface temperature increases stronger than the heating of the ABL, which increases the vertical gradient; and (ii) the near-surface wind speed is enhanced due to increased local pressure gradients, which increases the windshear and thus the sensible heat fluxes. Further, the warm plumes over the polynyas are efficiently advected over the pack ice. Thus heat is removed from above the polynyas and a strong temperature gradient is maintained, which enhances the ice production.

Constraining the assumptions on subgrid-scale thin ice was found to be difficult. The comparison of model-based IP with remote sensing estimates revealed large discrepancies. Further, large differences were found between the two remote sensing approaches. The usage of higher resolved MODIS data and ERA-Interim, compared to the approach of Willmes et al. (2011a) in which NCEP and AMSR-E data were used, nearly produced $+50 \%$ more ice. The configuration of $\mathrm{C} 05$ $50 / 1$, in which we assumed $50 \mathrm{~cm}$ thick grid-scale and $1 \mathrm{~cm}$ subgrid-scale thin ice, seems to be a realistic assumption in the marginal ice zone of the polynyas.

The resulting IP is close to the estimates of Willmes et al. (2011a), which we defined as a baseline for our sensitivity experiment. However, if for instance the results of MODIS2km were defined as a baseline, then even thinner ice might be considered. We are aware that our sea-ice module is simplified compared to more sophisticated sea-ice models, where the thin-ice thickness might be a prognostic variable and not a constant. However, despite our simple assumption, the results are promising and satisfactory in order to represent sea ice in a regional climate model in a computationally cheap approach. We further argue, based on our results, that assuming subgrid-scale open water within fractional sea ice, such as in Polar-WRF (Bromwich et al., 2009), leads to toohigh heat fluxes from the ocean into the atmosphere.

However, even if more sophisticated sea-ice models were used to estimate the IP, the issues remain of how to constrain parameters and to which data set to compare. It is not our intention to disentangle all factors controlling the estimation of sea-ice production based on different approaches, data sets, or models, but several issues are important in a general sense:

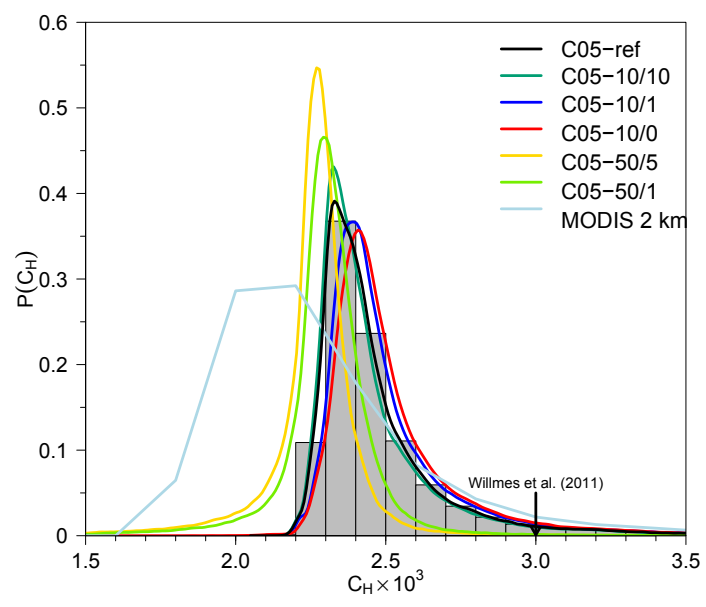

Figure 12. Probability density functions of the turbulent transfer coefficients for heat $\left(C_{\mathrm{H}}\right)$ within the Laptev Sea polynyas in the winter period (November-April) 2007/2008, aggregated within the four polynya masks. The grey bars show the histogram of $C_{\mathrm{H}}$ from C05-ref. Only values below $6 \times 10^{-3}$ have been used for the construction of this figure. The mean values of the $\mathrm{C} 05$ simulations are $\approx 2.5 \times 10^{-3}$ and the standard deviations are $\approx 0.28 \times 10^{-3}$, except for C05-50/5 and C05-50/1 where the mean values are $\approx 2.27 \times 10^{-3}$ and $\approx 2.31 \times 10^{-3}$, and the standard deviations are $\approx 0.18 \times 10^{-3}$, respectively. The constant value of $C_{\mathrm{H}}=3.0 \times 10^{-3}$ of Willmes et al. (2011a) is marked with an arrow. The mean $C_{\mathrm{H}}$ value derived from MODIS2km (November-March) is $C_{\mathrm{H}}=2.3 \pm 0.3 \times 10^{-3}$.

- Polynya area is affected by the definition of polynyas (e.g. SIC $\leq 70 \%$ or $h_{\mathrm{i}}<0.2 \mathrm{~m}$ ) and the horizontal resolution of the model and the satellite products.

- Heat loss is affected by the vertical temperature gradient, wind speed, parameterization of the energy balance components (turbulent fluxes), sea-ice thickness and properties, and the parameterization of the heat flux through the ice. Particularly important is the horizontal resolution of the atmospheric data set and the assumptions on the turbulent exchange coefficient for heat $\left(C_{\mathrm{H}}\right)$. Willmes et al. (2011a) assumed a constant value of $C_{\mathrm{H}}=3 \times 10^{-3}$. However, the mean values from C05 over polynyas (winter 2007/2008) are about $(2.5 \pm 0.28) \times 10^{-3}$ (Fig. 12), except for C05-50/5 and C05-50/1, which simulated slightly lower values of $(2.27 \pm 0.18) \times 10^{-3}$ and $(2.31 \pm 0.18) \times 10^{-3}$.

- Since the warm surface temperatures of polynyas and the resulting vertical temperature gradients are not well represented in ERA-Interim or NCEP, the usage of a high value of $C_{\mathrm{H}}$ seems to partly compensate for this issue. The $C_{\mathrm{H}}$ values based on MODIS data and ERAInterim are lower than simulated by CCLM with a mean of $C_{\mathrm{H}}=(2.3 \pm 0.3) \times 10^{-3}$. A similar probability distribution function was derived by Adams et al. (2013), who combined MODIS and NCEP. Because of the hor- 
izontal resolution of MODIS, polynyas are represented as anomalies in the surface temperature field, causing larger vertical temperature gradients and hence $C_{\mathrm{H}}$ values, which are comparable to CCLM.

- Surface temperatures in remote sensing approaches also depend on the number of swaths per day, e.g. clear-sky conditions, and their distribution over the day. If not equally distributed, the surface temperature and the ice production may be biased.

These influence factors together control differences between model and remote sensing sea-ice production estimates within polynyas. The polynya area is an obvious factor with the simple relationship: the larger the polynya area, the larger the sea-ice production. Note that sea-ice grows also outside polynyas, which was simulated by our model and contributed to the total IP. However, compared to the contribution of the polynya areas to the total, the IP of such areas is of minor importance. The explanations for differences in the heat or energy loss within polynyas is manifold. In our opinion, the most relevant factors, besides polynya area, are the thinice thickness and the parameterizations of the turbulent heat fluxes, in particular the differences in $C_{\mathrm{H}}$.

The complexity of these factors make a comparison of model and remote sensing studies difficult. It further indicates that some assumptions in the remote sensing approaches, such as a constant value for $C_{\mathrm{H}}$, might be oversimplified. Furthermore, a problematic issue is the usage of coarse atmospheric data sets, such as NCEP or ERA-Interim, for remote sensing approaches, if not combined with highresolution satellite products. The horizontal resolution of such atmospheric reanalysis data sets is not sufficient to represent polynyas adequately. Thus subsequent errors, such as wrong simulations of the atmospheric boundary layer over polynyas, are the consequence. These errors are then transferred to the remote sensing approach and might result in wrong sea-ice production estimates. From a modelling point of view the question arises of what reference for IP estimates should be used. This question is not easily answered and is still an open issue. A strategy might be a simultaneous application of both modelling and remote sensing approaches in order to compensate for weaknesses. This issue directly impedes the decision of an optimal model configuration.

According to our study, the approach of Willmes et al. (2011a) constitutes the closest reference because of the same satellite data that were used to derive polynya area at a comparable horizontal resolution. Although the definitions of polynyas are different, the assumption of $0.1 \mathrm{~m}$ thin ice in areas of SIC $\leq 70 \%$ is similar to the definition of $\leq 0.2 \mathrm{~m}$ as in Willmes et al. (2011a). Larger differences evolve from the assumptions made on $C_{\mathrm{H}}$ (Fig. 12) and the horizontal resolution of the atmospheric data. Given these deviations, the IP based on C05-ref and C05-50/1 is still close to the results of Willmes et al. (2011a). Although the use of MODIS, i.e. higher resolved satellite products, results in higher IP estimates, the reason for this is the higher horizontal resolution that causes larger polynya areas and not the representation of subgrid-scale energy fluxes within polynyas in ERA-Interim, which is still too coarse. For thicker ice the $C_{\mathrm{H}}$ values converge to $\leq 1.5 \times 10^{-3}$, a value also reported by Schröder et al. (2003).

Given these issues, the decision of which TIT should be used with the TA is another degree of freedom and cannot sufficiently be answered from our study. A justified assumption is to rely on MODIS TIT (Fig. 3). The mean derived TIT for the winter periods (November-March) 2002/2003$2014 / 2015$ is $13.5 \pm 0.5 \mathrm{~cm}$, which is slightly thicker than our assumed TIT in CCLM. Unfortunately, the MODIS TIT distribution for the polynya areas shows no maximum at a specific ice thickness, which gives no preference for the choice of the subgrid TIT for the tile approach.

\section{Conclusions}

In this study we quantified the ice production in the Laptev Sea polynyas for the winter 2007/2008 based on simulations with a regional atmospheric model (CCLM) and remote sensing data. A new tile approach for fractional sea ice, considering subgrid-scale thin ice, was implemented into CCLM. Besides a reference run, five sensitivity simulations with different assumptions on grid-scale and subgrid-scale ice within polynyas were performed. We further investigated the impact on the atmospheric boundary layer above polynyas.

The results show that the ice production is highly sensitive to the assumptions made on the ice thickness within polynyas. Compared to the estimated total winter ice production of $29.1 \mathrm{~km}^{3}$ of the reference simulation, the ice production more than doubled when subgrid-scale open water was assumed and increased by about $(+39 \%)$ for the most realistic assumptions based on remote sensing of ice thickness. The increase of the ice production is caused by a larger heat loss from the ocean, whose magnitude is proportional to the thin-ice thickness. Although the atmospheric boundary layer is heated by up to $+3{ }^{\circ} \mathrm{C}$ in the open-water configuration, strong vertical temperature gradients and associated high sensible heat fluxes at the surface were maintained. On one hand, the tile approach improves the physical representation of polynyas in CCLM because fractional sea ice is considered; on the other hand, a new degree of freedom is introduced to constrain the thin-ice thickness. The derivation of an optimal configuration for CCLM or other regional climate models remains difficult because of sparse observed ice thickness distributions within polynyas. We used remote sensing data as a baseline to constrain our configuration, but several issues were found which hamper such comparisons. At this point coupled atmosphere-ice-ocean models are needed to fully simulate feedback processes. 
In summary, realistic ice production estimates could be retrieved from our simulations. Neglecting subgrid-scale energy fluxes might considerably underestimate the ice production in coastal polynyas, such as in the Laptev Sea, with possible consequence on the Arctic sea-ice budget.

\section{Data availability}

The data used in this study are available on request from the authors (gutjahr@uni-trier.de or heinemann@uni-trier.de). 


\section{Appendix A: Sea-ice albedo scheme}

We implemented a modified Køltzow scheme (Køltzow, 2007) (Fig. A1) to replace the default treatment of sea-ice albedo, which was previously set to $\alpha_{\mathrm{i}}=0.75$ for ice thickness $>0.1 \mathrm{~m}$ and $\alpha_{\mathrm{i}}=0.2$ for ice thickness $\leq 0.1 \mathrm{~m}$ (Schröder et al., 2011). Furthermore, the Køltzow scheme includes a parameterization of melt ponds (see Køltzow, 2007, for details), yet they are of no importance for our study. The scheme is based on measurements retrieved during the Surface heat Budget of the Arctic Ocean (SHEBA) project (Uttal et al., 2002). It is forced by the surface temperature $T_{\mathrm{sfc}}$, which may be either the ice $\left(T_{\mathrm{i}}\right)$ or the snow surface temperature $\left(T_{\mathrm{s}}\right)$ (Fig. 4). If no snow cover is present the albedo only depends on the ice thickness. If the ice thickness exceeds the threshold value of $h_{\mathrm{c}}=0.2 \mathrm{~m}$, a snow cover on sea ice is assumed in accordance to the sea-ice module. Sea ice thicker than $h_{\mathrm{c}}$ is treated as thick ice and the albedo is estimated by

$\alpha_{\mathrm{i}}= \begin{cases}0.84 & \text { if } T_{\text {sfc }} \leq-2^{\circ} \mathrm{C} \\ 0.84-0.145\left(2+T_{\text {sfc }}\right) & \text { if } 0^{\circ} \mathrm{C}>T_{\text {sfc }}>-2^{\circ} \mathrm{C} . \\ 0.51 & \text { if } T_{\text {sfc }}>0{ }^{\circ} \mathrm{C}\end{cases}$

Køltzow (2007) sets the albedo for cold sea ice to a high value of 0.84 , which is supposed to include the effects of snow on sea ice in winter and spring. In the original scheme Køltzow (2007) set the threshold for thin ice to $h_{\mathrm{c}}=0.25 \mathrm{~m}$, but since the values above are only valid for snow-covered sea ice, we set $h_{\mathrm{c}}=0.2 \mathrm{~m}$ to be consistent with the sea-ice module.

For thin ice, we implemented a linear decrease towards the ocean albedo $\left(\alpha_{\mathrm{o}}=0.07\right)$ :

$\alpha_{\mathrm{i}}=\alpha_{\mathrm{o}}+\left(h_{\mathrm{i}} / h_{\mathrm{c}}\right) \cdot\left(\alpha_{\mathrm{c}}-\alpha_{\mathrm{o}}\right)$.

As a starting value we use $\alpha_{\mathrm{c}}=0.57$, the albedo of thick bare sea ice from Persson et al. (2002).

Figure A1 shows a summary of both cases. If the ice thickness is at least $0.2 \mathrm{~m}$ (bold black line) then the albedo is constant $\left(\alpha_{\mathrm{i}}=0.84\right)$ for cold, snow-covered sea ice. It decreases with increasing surface temperature if $-2{ }^{\circ} \mathrm{C}$ are exceeded. This temperature denotes a threshold where melting begins and sea ice is changing its albedo characteristics. In addition, if melt ponds occur (black solid line), the albedo is somewhat lower during the melting season. The fraction of melt ponds increases with $T_{\mathrm{sfc}}>-2{ }^{\circ} \mathrm{C}$ to a maximum of $22 \%$ (bold green line), an upper limit set by Køltzow (2007), and the albedo of melt ponds converges to the albedo of sea water (dashed green line). Furthermore, in Fig. A1 the thin-ice albedo is exemplified for four ice thicknesses which are not covered with snow and for which a constant albedo is assumed (thin black lines).

If the tile approach is used, subgrid-scale open water reduces the grid-average albedo accordingly, compared to a complete coverage with sea ice. A comparable, though less pronounced, reduction of albedo occurs if $1 \mathrm{~cm}$ thin-ice coverage is assumed for subgrid-scale open water.

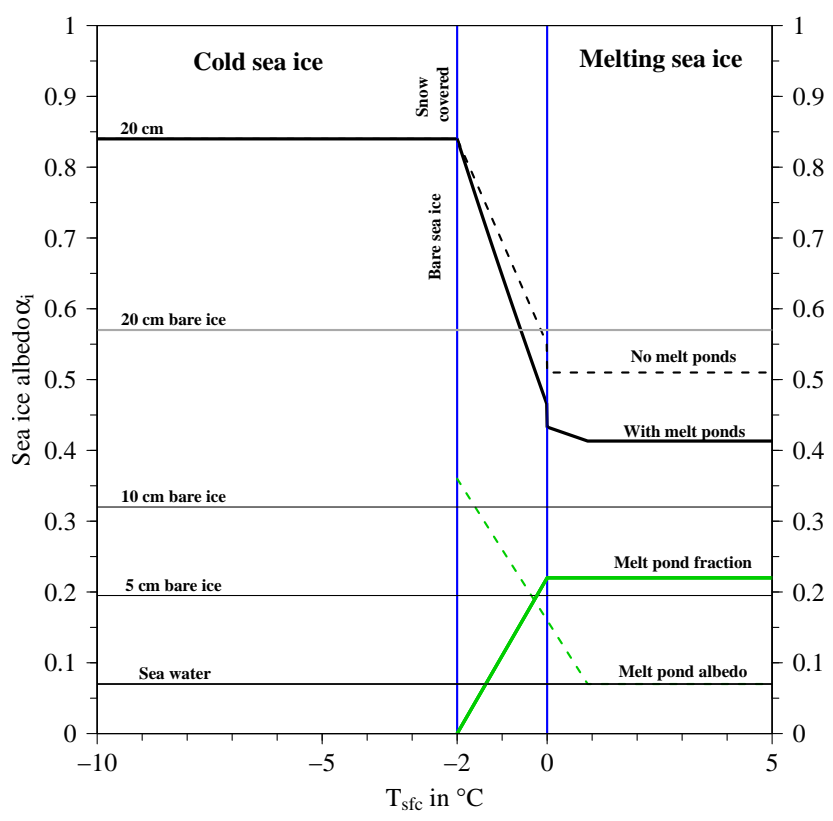

Figure A1. Sea-ice albedo resulting from the modified Køltzow scheme (Køltzow, 2007) depending on the ice surface temperature and thickness. Thereby the threshold thickness above which a snow cover of $10 \mathrm{~cm}$ is assumed is $h_{\mathrm{c}}=0.2 \mathrm{~m}$ (bold black line). In addition the melt pond fraction is shown as a function of the ice temperature (bold green line) and the resulting modification (dashed green line) of the sea-ice albedo (dashed black line). For bare seaice (thin black lines) a constant albedo value is assumed, which is linearly decreasing from 0.57 (Persson et al., 2002) at $20 \mathrm{~cm}$ ice thickness (bold grey line) to 0.07 (ocean albedo; Perovich and Grenfell, 1981), but constant over all surface temperatures, as shown in Eq. (A2). The vertical blue lines mark the transition range from cold to melting conditions.

\section{Appendix B: Implementation of the tile approach in CCLM}

In order to simulate the subgrid-scale energy fluxes over fractional sea ice, it is necessary to differentiate the energy balance and its components over water and ice. Over sea ice (index $k=i$ ) or ocean (index $k=o$ ) the total atmospheric heat flux (see Fig. 4) is

$Q_{\mathrm{A}, k}=K_{k}^{*}+L_{k}^{*}+H_{k}+E_{k}$,

with $K_{k}^{*}$ the net shortwave radiation, $L_{k}^{*}$ the net longwave radiation, $H_{k}$ the turbulent flux of sensible heat, and $E_{k}$ the turbulent flux of latent heat.

All routines of CCLM, except the sea-ice and the turbulence module, calculate with grid-box averaged coefficients or fluxes (flux averaging approach; Vihma, 1995), which is best suited if the sea-ice module only requires the fluxes over ice (Lüpkes and Gryanik, 2015). The procedure is described in Sect. B3.

As initial data the module requires the sea surface temperature, the sea-ice fraction $(A)$ and extent, SIT, the surface 
temperature of sea ice $\left(T_{\mathrm{i}}\right)$, specific humidity at the ice surface, the wind-speed on the lowest model level, and incoming longwave and shortwave radiation (see Schröder et al., 2011, for more details).

The calculation of the components of the energy balance equations are shown in the next subsections.

\section{B1 Shortwave radiation}

The grid-box average of the albedo $\alpha_{\mathrm{m}}$ (index "m" for "mixed") is calculated as

$\alpha_{\mathrm{m}}=A \cdot \alpha_{\mathrm{i}}+(1-A) \cdot \alpha_{\mathrm{o}}$,

with $A$ the sea-ice fraction, $\alpha_{\mathrm{o}}=0.07$ the albedo of the ocean, and $\alpha_{\mathrm{i}}=f\left(T_{\mathrm{i}}, h\right)$ the albedo of sea ice as a function of seaice temperature $\left(T_{\mathrm{i}}\right)$ and thickness $(h)$ (see Sect. A). Based on this mixed albedo the upward shortwave radiation is calculated as

$K \uparrow_{\mathrm{m}}=\alpha_{\mathrm{m}} \cdot K \downarrow$,

with $K \downarrow$ the incoming shortwave radiation. The grid-box averaged net shortwave radiation is calculated as

$K_{\mathrm{m}}^{*}=K \downarrow-K \uparrow_{\mathrm{m}}=\left(1-\alpha_{\mathrm{m}}\right) \cdot K \downarrow$.

This grid-box averaged net shortwave radiation is the input for the sea-ice module where the upward shortwave radiation over ice $K \uparrow_{\mathrm{i}}$ is calculated as

$K \uparrow_{\mathrm{i}}=\alpha_{\mathrm{i}} \cdot K \downarrow$.

The final net shortwave radiation over sea ice or ocean becomes

$K_{k}^{*}=\left(1-\alpha_{k}\right) \cdot K \downarrow=\frac{1-\alpha_{k}}{1-\alpha_{\mathrm{m}}} \cdot K_{\mathrm{m}}^{*}$,

where the index $k$ refers either to $i$ (sea ice) or $o$ (ocean).

\section{B2 Longwave radiation}

The subgrid-scale ocean surface temperature $\left(T_{0}\right)$ is assumed to be at the freezing point $\left(-1.7^{\circ} \mathrm{C}\right)$ if open water is assumed, or to be a prognostic variable if a thin-ice cover is assumed. The ice surface temperature $\left(T_{\mathrm{i}}\right)$ is also a prognostic variable in the sea-ice module.

To account for subgrid-scale longwave radiation, we calculate the upward longwave radiation over sea ice and ocean as

$L \uparrow_{k}=\epsilon \sigma T_{k}^{4}-(1-\epsilon) L \downarrow$,

with $\sigma$ the Stefan-Boltzmann constant, $L \downarrow$ the incoming longwave radiation, $\epsilon$ the surface emissivities of sea water and ice, which are assumed to be equal $(\epsilon=0.996)$, and $T_{k}$ the surface temperature of ice or ocean.

Then the net longwave radiation balance over sea ice or ocean becomes

$L_{k}^{*}=L \downarrow-L \uparrow k$.

\section{B3 Turbulent fluxes of sensible and latent heat}

We modified the parameterization of the turbulent fluxes of sensible $(H)$ and latent heat $(E)$ within a grid box, in contrast to the standard version of CCLM and the sea-ice module of Schröder et al. (2011). Over sea ice or ocean the roughness length $z_{0}$ and the turbulent coefficients of heat and moisture $C_{\mathrm{H}}$ were previously calculated from the predominant surface type of a grid box: ice or sea water. We modified this procedure by a tile approach; now the fluxes are calculated both for sea ice and ocean within a grid box with different $z_{0}$ and $C_{\mathrm{H}}$. Afterwards they are averaged in a "flux-averaging approach" and an average $C_{\mathrm{H}}$ is calculated for other modules. The calculation of the momentum flux is not modified and for the details of the calculation we refer the reader to Doms et al. (2011).

In CCLM a stability- and roughness-length-dependent surface flux formulation is used, which is based on flux calculations after Louis (1979). The fluxes are calculated with a bulk approach:

$H=-\rho c_{p} C_{\mathrm{H}}\left|v_{\mathrm{h}}\right|\left(\Theta_{\mathrm{sfc}}-\Theta\right)$,

$E=-\rho L_{\mathrm{f}} C_{\mathrm{H}}\left|v_{\mathrm{h}}\right|\left(q_{\mathrm{sfc}}-q\right)$,

with $\rho$ the air density, $c_{p}$ the heat capacity of air, and $\Theta$ and $\Theta_{\text {sfc }}$ the potential temperature at the lowest model layer and at the surface (ice or ocean). $q$ and $q_{\mathrm{sfc}}$ are the specific humidity at the lowest model layer and at the surface (ice or ocean), $L_{\mathrm{f}}$ the latent heat of fusion (and sublimation in case of sea ice), $\left|v_{\mathrm{h}}\right|=\sqrt{u^{2}+v^{2}}$ the absolute wind speed, and $C_{\mathrm{H}}$ the turbulent transfer coefficient for heat and moisture.

To calculate the turbulent transfer coefficients it is first necessary to calculate the roughness length of seawater $\left(z_{0, \mathrm{o}}\right)$ and sea ice $\left(z_{0, \mathrm{i}}\right)$. In case of sea ice we set $z_{0, \mathrm{i}}=0.001 \mathrm{~m}$ as in Schröder et al. (2011). Over open water a modified Charnock formula is used (see Doms et al., 2011). In case of $H$ and $E$, we assume the additional roughness length for heat $z_{\mathrm{h}}$ (Doms et al., 2011) to be equal to $z_{0}$ over subgrid-scale open ocean within the sea-ice cover.

The transfer coefficients are calculated over sea ice $\left(C_{\mathrm{H}, \mathrm{i}}\right)$ and ocean $\left(C_{\mathrm{H}, \mathrm{o}}\right)$. The turbulent fluxes over sea ice $\left(H_{\mathrm{i}}, E_{\mathrm{i}}\right)$ and ocean $\left(H_{\mathrm{o}}, E_{\mathrm{o}}\right)$ can be retrieved by inserting these coefficients into Eqs. (B9)-(B10). Then all terms of Eq. (B1) are known to solve the energy balance over both surface types.

The fluxes of sensible and latent heat, the turbulent transfer coefficient for heat, and the surface temperature are averaged according to the sea-ice concentration $A$ :

$$
\begin{aligned}
& H_{\mathrm{m}}=A \cdot H_{\mathrm{i}}+(1-A) \cdot H_{\mathrm{o}}, \\
& E_{\mathrm{m}}=A \cdot E_{\mathrm{i}}+(1-A) \cdot E_{\mathrm{o}}, \\
& C_{\mathrm{Hm}}=A \cdot C_{\mathrm{H}, \mathrm{i}}+(1-A) \cdot C_{\mathrm{H}, \mathrm{o}}, \\
& T_{\mathrm{sfc}}=A \cdot T_{\mathrm{i}}+(1-A) \cdot T_{\mathrm{o}} .
\end{aligned}
$$

The grid-averaged temperature fields are used for the comparisons in Sect. 5. 
Author contributions. Oliver Gutjahr implemented the tile approach and other modifications to the CCLM source code, conducted the CCLM simulations, designed the study and wrote the paper. Günther Heinemann assisted in designing the experiments and the structure of the paper, as well as the writing process. Andreas Preußer wrote the section on MODIS and calculated the seaice production from MODIS data. Sascha Willmes calculated the ice production rates based on AMSR-E and NCEP and assisted in the discussion on the comparison of remote sensing and modelling results. Clemens Drüe contributed to the translation of the equations into source code.

Acknowledgements. This work was funded by the German Federal Ministry of Education and Research (BMBF) under grant 03G0833D, and is part of the German-Russian Transdrift project. We thank the CLM community and the German Meteorological Service for providing the basic COSMO-CLM model. The AMSR-E data were provided by the University of Bremen, the MODIS data were provided by the US National Snow and Ice Data Center, ERA-Interim by the ECMWF, and the PIOMAS data set by the Polar Science Center (University of Washington). Finally, we thank the DKRZ for providing computational time and two anonymous reviewers for critical comments.

Edited by: D. Notz

Reviewed by: two anonymous referees

\section{References}

Aagard, K., Coachman, L., and Carmack, E.: On the halocline of the Arctic Ocean, Deep-Sea Res., 28, 529-545, doi:10.1016/01980149(81)90115-1, 1981.

Adams, S., Willmes, S., Heinemann, G., Rozman, P., Timmermann, R., and Schröder, D.: Evaluation of simulated seaice concentrations from sea-ice/ocean models using satellite data and polynya classification methods, Polar Res., 30, 7124, doi:10.3402/polar.v30i0.7124, 2011.

Adams, S., Willmes, S., Schroeder, D., Heinemann, G., Bauer, M., and Krumpen, T.: Improvement and sensitivity analysis of thermal thin-ice retrievals, IEEE T. Geosci. Remote, 51, 3306-3318, 2013.

Aksenov, Y., Ivanov, V. V., Nurser, A. J. G., Bacon, S., Polyakov, I. V., Coward, A. C., Garabato, A. C. N., and Moeller, A. B.: The Arctic circumpolar boundary current, J. Geophys. Res., 116, C09017, doi:10.1029/2010JC006637, 2011.

Backhaus, J. A., Fohrmann, H., Kaempf, J., and Rubina, A.: Formation and export of water masses produced in Arctic shelf polynyas - Process studies of oceanic convection, J. Mar. Sci., 54, 366-382, 1997.

Baldauf, M.: A new fast-waves solver for the Runge-Kutta dynamical core, Tech. rep. No. 21, Deutscher Wetterdienst, Offenbach am Main, 2013.

Bareiss, J. and Görgen, K.: Spatial and temporal variability of sea ice in the Laptev Sea: Analyses and review of satellite passivemicrowave data and model results, 1979 to 2002, Global Planet. Change, 48, 28-54, doi:10.1016/j.gloplacha.2004.12.004, 2005.
Bauch, D., Schlosser, P., and Fairbanks, R. F.: Freshwater balance and the sources of deep and bottom waters in the Arctic Ocean inferred from the distribution of $\mathrm{H}_{2}^{18} \mathrm{O}$, Prog. Oceanogr., 35, 5380, doi:10.1016/0079-6611(95)00005-2, 1995.

Bauch, D., Dmitrenko, I. A., Wegner, C., Hölemann, J., Kirillov, S. A., Timokhov, L. A., and Kassens, H.: Exchange of Laptev Sea and Arctic Ocean halocline waters in response to atmospheric forcing, J. Geophys. Res., 114, C05008, doi:10.1029/2008JC005062, 2009.

Bauer, M., Schröder, D., Heinemann, G., Willmes, S., and Ebner, L.: Quantifying polynya ice production in the Laptev Sea with the COSMO model, Polar Res., 32, 20922, doi:10.3402/polar.v32i0.20922, 2013.

Bowen, I. S.: The ratio of heat losses by conduction and by evaporation for any water surface, Physiol. Rev., 27, 779-787, 1926.

Bromwich, D. H., Hines, K. M., and Bai, L.-S.: Development and testing of Polar Weather Research and Forecasting model: 2. Arctic Ocean, J. Geophys. Res.-Atmos., 114, D08122, doi:10.1029/2008JD010300, 2009.

Dee, D. P., Uppala, S. M., Simmons, A. J., Berrisford, P., Poli, P., Kobayashi, S., Andrae, U., Balmaseda, M. A., Balsamo, G., Bauer, P., Bechtold, P., Beljaars, A. C. M., van de Berg, L., Bidlot, J., Bormann, N., Delsol, C., Dragani, R., Fuentes, M., Geer, A. J., Haimberger, L., Healy, S. B., Hersbach, H., Hólm, E. V., Isaksen, L., Kåberg, P., Köhler, M., Matricardi, M., McNally, A. P., Monge-Sanz, B. M., Morcrette, J.-J., Park, B.-K., Peubey, C., de Rosnay, P., Tavolato, C., Thépaut, J.-N., and Vitart, F.: The ERA-Interim reanalysis: configuration and performance of the data assimilation system, Q. J. Roy. Meteorol. Soc., 137, 553597, doi:10.1002/qj.828, 2011.

Dethleff, D., Loewe, P., and Kleine, E.: The Laptev Sea flaw lead - detailed investigation on ice formation and export during 1991/1992 winter season, Cold. Reg. Sci. Technol., 27, 225-243, doi:10.1016/S0165-232X(98)00005-6, 1998.

Dmitrenko, I., Hölemann, J. A., Tyshko, K., Churun, V., Kirillov, S., and Kassens, H.: The Laptev Sea flaw polynya, Russian Arctic: effects on the mesoscale hydrography, Ann. Glaciol., 33, 373376, doi:10.3189/172756401781818455, 2001.

Dmitrenko, I. A., Tyshko, K. N., Kirillov, S. A., Eicken, H., Hölemann, J., and Kassens, H.: Impact of flaw polynyas on the hydrography of the Laptev Sea, Global Planet. Change, 48, 9-27, doi:10.1016/j.gloplacha.2004.12.016, 2005.

Dmitrenko, I. A., Kirillov, S. A., Tremblay, L. B., Bauch, D., and Willmes, S.: Sea-ice production over the Laptev Sea shelf inferred from historical summer-to-winter hydrographic observations of 1960s-1990s, Geophys. Res. Lett., 36, L13605, doi:10.1029/2009GL038775, 2009.

Dmitrenko, I. A., Kirillov, S. A., Bloshkina, E., and Lenn, Y.-D.: Tide-induced vertical mixing in the Laptev Sea coastal polynya, J. Geophys. Res.-Oceans, 117, C00G14, doi:10.1029/2011JC006966, 2012.

Doms, G., Förster, J., Heise, E., Herzog, H., Raschendorfer, M., Reinhardt, T., Ritter, B., Schrodin, R., Schulz, J.-P., and Vogel, G.: A Description of the Nonhydrostatic Regional COSMOModel Part II: Physical Parameterization, Consortium for Smallscale Modelling, Deutscher Wetterdienst, Offenbach, Germany, 2011.

Ebner, L., Schröder, D., and Heinemann, G.: Impact of Laptev Sea flaw polynyas on the atmospheric boundary layer and ice produc- 
tion using idealized mesoscale simulations, Polar Res., 30, 7010, doi:10.3402/polar.v30i0.7210, 2011.

Eicken, H., Dmitrenko, I. A., Tyshko, K., Darovskikh, A., Dierking, W., Blahak, U., Groves, J., and Kassens, H.: Zonation of the Laptev Sea landland ice cover and its importance in a frozen estuary, Global Planet. Change, 48, 55-83, doi:10.1016/j.gloplacha.2004.12.005, 2005.

Haid, V., Timmermann, R., Ebner, L., and Heinemann, G.: Atmospheric forcing of coastal polynyas in the south-western Weddell Sea, Antarct. Sci., 27, 388-402, doi:10.1017/S0954102014000893, 2015.

Hall, D., Key, J., Casey, K., Riggs, G., and Cavalieri, D.: Sea ice surface temperature product from MODIS, IEEE T. Geosci. Remote, 42, 1076-1087, 2004.

Heinemann, G. and Kerschgens, M.: Comparison of methods for area-averaging surface energy fluxes over heterogeneous land surfaces using high-resolution non-hydrostatic simulations, Int. J. Climatol., 25, 379-403, doi:10.1002/joc.1123, 2005.

Heinemann, G. and Rose, L.: Surface energy balance, parameterizations of boundary-layer heights and the application of resistance laws near an Antarctic Ice Shelf front, Bound.-Lay. Meteorol., 51, 123-158, doi:10.1007/BF00120464, 1990.

Heinemann, G., Helbig, A., and Ernsdorf, T.: Meteorological measurements at the ice edge of the West New Siberian Polynya, in: Russian-German cooperation Laptev-Sea System: Expedition TRANSDRIFT XIII, 5 April-5 May 2008, edited by: Kassens, H. and Volkmann-Lark, K., Sekretariat System Laptev-See, Kiel, 66, 11-22, 2010.

Hines, K. M., Bromwich, D. H., Bai, L., Bitz, C. M., Powers, J. G., and Manning, K. W.: Sea Ice Enhancements to Polar WRF, Mon. Weather Rev., 143, 2363-2385, doi:10.1175/MWR-D-1400344.1, 2015.

Ivanov, V. V. and Golovin, P.: Observations and modeling of dense water cascading from the northwestern Laptev Sea, J. Geophys. Res., 112, C09003, doi:10.1029/2006JC003882, 2007.

Iwamoto, K., Ohshima, K. I., and Tamura, T.: Improved mapping of sea ice production in the Arctic Ocean using AMSR-E thin ice thickness algorithm, J. Geophys. Res.-Oceans, 119, 3574-3594, doi:10.1002/2013JC009749, 2014.

Johnson, M. A. and Polyakov, I. V.: The Laptev Sea as a source for recent Arctic Ocean salinity changes, Geophys. Res. Lett., 28, 2017-2020, doi:10.1029/2000GL012740, 2001.

Køltzow, M.: The effect of a new snow and sea ice albedo scheme on regional climate model simulations, J. Geophys. Res., 112, D07110, doi:10.1029/2006JD007693, 2007.

Krumpen, T., Hölemann, J. A., Willmes, S., Morales Maqueda, M. A., Busche, T., Dmitrenko, I. A., Gerdes, R., Haas, C., Heinemann, G., Hendricks, S., Kassens, H., Rabenstein, L., and Schröder, D.: Sea ice production and water mass modification in the eastern Laptev Sea, J. Geophys. Res., 116, C05014, doi:10.1029/2010JC006545, 2011.

Krumpen, T., Janout, M., Hodges, K. I., Gerdes, R., GirardArdhuin, F., Hölemann, J. A., and Willmes, S.: Variability and trends in Laptev Sea ice outflow between 1992-2011, The Cryosphere, 7, 349-363, doi:10.5194/tc-7-349-2013, 2013.

Launiainen, J. and Vihma, T.: Derivation of turbulent surface fluxes - An iterative flux-profile method allowing arbitrary observing heights, Environ. Softw., 5, 113-124, doi:10.1016/02669838(90)90021-W, 1990.
Louis, J.-F.: A parametric model of vertical eddy fluxes in the atmosphere, Bound.-Lay. Meteorol., 17, 187-202, doi:10.1007/BF00117978, 1979.

Lüpkes, C. and Gryanik, V. M.: A stability dependent parametrization of transfer coefficients for momentum and heat over polar sea ice to be used in climate models, J. Geophys. Res.-Atmos., 120, 552-581, doi:10.1002/2014JD022418, 2015.

Markus, T. and Burns, B. A.: A method to estimate subpixel-scale coastal polynyas with satellite passive microwave data, J. Geophys. Res.-Oceans, 100, 4473-4487, doi:10.1029/94JC02278, 1995.

Martin, S. and Cavalieri, D.: Contributions of the Siberian shelf polynyas to the Arctic Ocean intermediate and deep water, J. Geophys. Res.-Oceans, 94, 12725-12738, doi:10.1029/JC094iC09p12725, 1989.

Martin, S. and Kauffmann, P.: A field and laboratory study of wave dumping by grease ice, J. Glacial., 27, 293-313, 1981.

Massom, R. A., Harris, P. T., Michael, K. J., and Potter, M.: The distribution and formative processes of latent-heat polynyas in East Antarctica, Ann. Glaciol., 27, 420-426, 1998.

Mellor, G. L. and Yamada, T.: A Hierarchy of Turbulence Closure Models for Planetary Boundary Layers, J. Atmos. Sci., 31, 1791-1806, doi:10.1175/15200469(1974)031<1791:AHOTCM>2.0.CO;2, 1974.

Mironov, D., Ritter, B., Schulz, J.-P., Buchhold, M., Lange, M., and Machulskaya, E.: Parameterisation of sea and lake ice in numerical weather prediction models of the German Weather Service, Tellus A, 64, 17330, doi:10.3402/tellusa.v64i0.17330, 2012.

Morales Maqueda, M. A., Willmott, A. J., and Biggs, N. R. T.: Polynya Dynamics: a Review of Observations and Modeling, Rev. Geophys., 42, RG1004, doi:10.1029/2002RG000116, 2004.

Paul, S., Willmes, S., Gutjahr, O., Preußer, A., and Heinemann, G.: Spatial Feature Reconstruction of Cloud-Covered Areas in Daily MODIS Composites, Rem. Sens., 7, 5042-5056, doi:10.3390/rs70505042, 2015.

Perovich, D. K. and Grenfell, T. C.: Laboratory studies of the optical properties of young sea ice, J. Glaciol., 27, 331-346, 1981.

Persson, P. O. G., Fairall, C. W., Andreas, E. L., Guest, P., and Perovich, D. K.: Measurements near the Atmospheric Surface Flux Group tower at SHEBA: Near-surface conditions and surface energy budget, J. Geophys. Res., 107, 8045, doi:10.1029/2000JC000705, 2002.

Preußer, A., Heinemann, G., and Willmes: Multi-Decadal variability of Thin-Ice Dynamics and Ice Production in the North Water Polynya by means of Passive Microwave and Thermal Infrared Satellite Imagery, Rem. Sens., 7, 15844-15867, doi:10.3390/rs71215807, 2015a.

Preußer, A., Willmes, S., Heinemann, G., and Paul, S.: Thin-ice dynamics and ice production in the Storfjorden polynya for winter-seasons 2002/2003-2013/2014 using MODIS thermal infrared imagery, The Cryosphere, 9, 1063-1073, doi:10.5194/tcd8-5763-2014, $2015 b$.

Riggs, G. and Hall, D.: MODIS Sea Ice Products User Guide to Collection 6, NSIDC, url:http://nsidc.org/data/docs/daac/modis/pdf/ modis-sea-ice-user-guide-C6.pdf (last access: December 2016) 2006.

Rigor, I. G. and Colony, R. L.: Sea-ice production and transport of pollutants in the Laptev Sea, Sci. Total Environ., 202, 89-110, 1997. 
Ritter, B. and Geleyn, J.-F.: A Comprehensive Radiation Scheme for Numerical Weather Prediction Models with Potential Applications in Climate Simulations, Mon. Weather Rev., 120, 303-325, doi:10.1175/1520-0493(1992)120<0303:ACRSFN>2.0.CO;2, 1992.

Rockel, B., Will, A., and Hense, A.: The Regional Climate Model COSMO-CLM (CCLM), Meteorol. Z., 17, 347-348, 2008.

Rudels, B., Friedrich, H. J., and Quadfasel, D.: The Arctic circumpolar boundary current, Deep-Sea Res., 46, 1023-1062, doi:10.1016/S0967-0645(99)00015-6, 1999.

Schröder, D., Vihma, T., Kerber, A., and Brümmer, B.: On the parameterization of turbulent surface fluxes over heterogeneous sea ice surfaces, J. Geophys. Res.-Oceans, 108, 3195, doi:10.1029/2002JC001385, 2003.

Schröder, D., Heinemann, G., and Willmes, S.: The impact of a thermodynamic sea-ice module in the COSMO numerical weather prediction model on simulations for the Laptev Sea, Siberian Arctic, Polar Res., 30, 6334, doi:10.3402/polar.v30i0.6334, 2011.

Schweiger, A., Lindsay, R., Zhang, J., Steele, M., Stern, H., and Kwok, R.: Uncertainty in modeled Arctic sea ice volume, J. Geophys. Res.-Oceans, 116, C00D06, doi:10.1029/2011JC007084, 2011.

Smedsrud, L. H. and Martin, T.: Grease ice in basinscale sea-ice ocean models, Ann. Glaciol., 56, 295-306, doi:10.3189/2015AoG69A765, 2015.

Smith, S. D., Muench, R. D., and Pease, C. H.: Polynyas and leads: An overview of physical processes and environment, J. Geophys. Res.-Oceans, 95, 9461-9479, doi:10.1029/JC095iC06p09461, 1990.

Spreen, G., Kaleschke, L., and Heygster, G.: Sea ice remote sensing using AMSR-E 89-GHz channels, J. Geophys. Res.-Oceans, 113, C02S03, doi:10.1029/2005JC003384, 2008.

Steppeler, J., Doms, G., Schättler, U., Bitzer, H. W., Gassmann, A., Damrath, U., and Gregoric, G.: Meso-gamma scale forecasts using the nonhydrostatic model LM, Meteorol. Atmos. Phys., 82, 75-96, doi:10.1007/s00703-001-0592-9, 2003.

Tamura, T. and Ohshima, K. I.: Mapping of sea ice production in the Arctic coastal polynyas, J. Geophys. Res.-Oceans, 116, C07030, doi:10.1029/2010JC006586, 2011.

Timokhov, L. A.: Regional characteristics of the Laptev and the East Siberian seas: climate, topography, ice phases, thermohaline regime, circulation, Ber. Polarforsch., 114, 15-32, 1994.

Uttal, T., Curry, J. A., Mcphee, M. G., Perovich, D. K., Moritz, R. E., Maslanik, J. A., Guest, P. S., Stern, H. L., Moore, J. A., Turenne, R., Heiberg, A., Serreze, M. C., Wylie, D. P., Persson, O. G., Paulson, C. A., Halle, C., Morison, J. H., Wheeler, P. A., Makshtas, A., Welch, H., Shupe, M. D., Intrieri, J. M., Stamnes, K., Lindsey, R. W., Pinkel, R., Pegau, W. S., Stanton, T. P., and Grenfeld, T. C.: Surface Heat Budget of the Arctic Ocean, B. Am. Meteorol. Soc., 83, 255-275, doi:10.1175/15200477(2002)083<0255:SHBOTA>2.3.CO;2, 2002.
Van Pham, T., Brauch, J., Dieterich, C., Frueh, B., and Ahrens, B.: New coupled atmosphere-ocean-ice system COSMOCLM/NEMO: assessing air temperature sensitivity over the North and Baltic Seas, Oceanologia, 56, 167-189, doi:10.5697/oc.56-2.167, 2014.

Vihma, T.: Subgrid parameterization of surface heat and momentum fluxes over polar oceans, J. Geophys. Res.-Oceans, 100, 2262522646, doi:10.1029/95JC02498, 1995.

Wicker, L. J. and Skamarock, W. C.: Time-Splitting Methods for Elastic Models Using Forward Time Schemes, Mon. Weather Rev., 130, 2088-2097, doi:10.1175/15200493(2002)130<2088:TSMFEM>2.0.CO;2, 2002.

Willmes, S., Krumpen, T., Adams, S., Rabenstein, L., and Haas, C.: Cross-validation of polynya monitoring methods from multisensor satellite and airborne data: A case study, Can. J. Remote Sens., 36, 196-210, doi:10.5589/m10-012, 2010.

Willmes, S., Adams, S., Schröder, D., and Heinemann, G.: Spatiotemporal variability of polynya dynamics and ice production in the Laptev Sea between the winters of 1979/80 and 2007/08, Polar Res., 30, 5971, doi:10.3402/polar.v30i0.5971, $2011 \mathrm{a}$.

Willmes, S., Adams, S., Schröder, D., and Heinemann, G.: Daily ice production in the Laptev Sea polynyas, doi:10.1594/PANGAEA.793228, in: supplement to: Willmes, S. et al. (2011): Spatio-temporal variability of polynya dynamics and ice production in the Laptev Sea between the winters of 1979/80 and 2007/08, Polar Res., 30, 5971, doi:10.3402/polar.v30i0.5971, $2011 \mathrm{~b}$.

Yu, Y. and Lindsay, R.: Comparison of thin ice thickness distributions derived from RADARSAT Geophysical Processor System and advanced very high resolution radiometer data sets, J. Geophys. Res., 108, 3387, doi:10.1029/2002JC001319, 2003.

Yu, Y. and Rothrock, D. A.: Thin ice thickness from satellite thermal imagery, J. Geophys. Res., 101, 25753-25766, 1996.

Zhang, J. and Rothrock, D. A.: Modeling Global Sea Ice with a Thickness and Enthalpy Distribution Model in Generalized Curvilinear Coordinates, Mon. Weather Rev., 131, 845-861, doi:10.1175/1520-0493(2003)131<0845:MGSIWA>2.0.CO;2, 2003. 